Article

\title{
Synthesis and Structure-Activity Relationship Analysis of 5-HT 7 Receptor Antagonists: Piperazin-1-yl Substituted Unfused Heterobiaryls
}

\author{
Lucjan Strekowski ${ }^{1, *}$, Jarosław Sączewski ${ }^{2, *}$, Elizabeth A. Raux ${ }^{1}$, Nilmi T. Fernando ${ }^{1}$, \\ Jeff Klenc ${ }^{1}$, Shirish Paranjpe ${ }^{1}$, Aldona Raszkiewicz ${ }^{1}$, Ava L. Blake ${ }^{1}$, Adam J. Ehalt ${ }^{1}$, \\ Samuel Barnes ${ }^{1}$, Timothy C. Baranowski ${ }^{1}$, Shannon M. Sullivan ${ }^{1}$, Grzegorz Satała ${ }^{3}$ \\ and Andrzej J. Bojarski ${ }^{3}$ \\ 1 Department of Chemistry, Georgia State University, Atlanta, Georgia, GA 30302, USA; \\ earaux@gmail.com (E.A.R.); fernando.nilmi@gmail.com (N.T.F.); jklenc@merchantgould.com (J.K.); \\ shirishp007@gmail.com (S.P.); aldona.paluchowska@urpl.gov.pl (A.R.); ablake@bakerlaw.com (A.L.B.); \\ adamehalt@gmail.com (A.J.E.); sambarnes2@gmail.com (S.B.); tcb@bellsouth.net (T.C.B.); \\ ssullivan@yahoo.com (S.M.S.) \\ 2 Department of Chemical Technology of Drugs, Medical University of Gdańsk, \\ Aleja Generała Józefa Hallera 107, Gdańsk 80-416, Poland \\ 3 Department of Medicinal Chemistry, Institute of Pharmacology, Polish Academy of Sciences, Smętna 12, \\ Kraków 31-343, Poland; satala@if-pan.krakow.pl (G.S.); bojarski@if-pan.krakow.pl (A.J.B.) \\ * Correspondence: lucjan@gsu.edu (L.S.); js@gumed.edu.pl (J.S.); \\ Tel.: +1-770-931-4224 (L.S.); +48-58-349-1648 (J.S.)
}

Academic Editor: Derek J. McPhee

Received: 27 February 2016; Accepted: 22 March 2016; Published: 31 March 2016

\begin{abstract}
A series of piperazin-1-yl substituted unfused heterobiaryls was synthesized as ligands of the $5-\mathrm{HT}_{7}$ receptors. The goal of this project was to elucidate the structural features that affect the $5-\mathrm{HT}_{7}$ binding affinity of this class of compounds represented by the model ligand 4-(3-furyl)-2-(4-methylpiperazin-1-yl)pyrimidine (2). The SAR studies included systematical structural changes of the pyrimidine core moiety in 2 to quinazoline, pyridine and benzene, changes of the 3-furyl group to other heteroaryl substituents, the presence of various analogs of the 4-methylpiperazin-1-yl group, as well as additional substitutions at positions 5 and 6 of the pyrimidine. Substitution of position 6 of the pyrimidine in the model ligand with an alkyl group results in a substantial increase of the binding affinity (note a change in position numbers due to the nomenclature rules). It was also demonstrated that 4-(3-furyl) moiety is crucial for the $5-\mathrm{HT}_{7}$ binding affinity of the substituted pyrimidines, although, the pyrimidine core can be replaced with a pyridine ring without a dramatic loss of the binding affinity. The selected ethylpyrimidine (12) and butylpyrimidine (13) analogs of high $5-\mathrm{HT}_{7}$ binding affinity showed antagonistic properties in cAMP functional test and varied selectivity profile-compound $\mathbf{1 2}$ can be regarded as a dual $5-\mathrm{HT}_{7} / 5-\mathrm{HT}_{2 \mathrm{~A}} \mathrm{R}$ ligand, and $\mathbf{1 3}$ as a multi-receptor $\left(5-\mathrm{HT}_{7}, 5-\mathrm{HT}_{2 \mathrm{~A}}, 5-\mathrm{HT}_{6}\right.$ and $\left.\mathrm{D}_{2}\right)$ agent.
\end{abstract}

Keywords: $5-\mathrm{HT}_{7}$ receptor ligands; 5-HT; serotonin; synthesis; structure-affinity relationships (SAR); $\mathrm{N}$-methylpiperazine; 3-furyl

\section{Introduction}

For more than 60 years, the studies on the role of serotonin (5-HT) within the central nervous system (CNS) have constantly provided evidence of the involvement of 5-HT receptors in the action of various psychiatric drugs. It is now evident that deregulation of serotonergic signaling is associated with pathogenesis of severe neuropsychological disorders like depression [1,2] Alzheimer's 
disease [3,4] or schizophrenia [5], and not surprisingly the 5-HT signaling system is one of the major focuses of various CNS drug development strategies [6].

Among the plethora of functions influenced by fourteen 5-HT receptor subtypes, activation of $5-\mathrm{HT}_{7}$ receptors $\left(5-\mathrm{HT}_{7} \mathrm{R}\right)$ in the CNS regulates circadian rhythms (facilitates diurnal phase shift and REM sleep) $[7,8]$, thermoregulation (induces hypothermia) $[9,10]$ and cognitive processes by facilitation of long and short-term memory consolidation [11-13]. Moreover, the presence of 5-HT receptors in key cerebral areas as well as high affinity of numerous antidepressants and antipsychotics for the $5-\mathrm{HT}_{7}$ receptors, indicate their potential role in depression and schizophrenia [14-17]. The results of pre-clinical studies have shown that both genetic inactivation and pharmacological blockade of the $5-\mathrm{HT}_{7}$ receptors leads to antidepressant-like effects in animal models of depression $[14,16]$. Similarly, antagonism at $5-\mathrm{HT}_{7}$ receptors is one of the key pharmacological features of vortioxetine, an atypical antidepressant that was approved for medication in 2013 by the U.S. FDA [18]. Therefore, the new individual therapies targeting the blockade of $5-\mathrm{HT}_{7}$ receptors in combination with using antidepressants are currently under investigation [19].

In relation to schizophrenic disorders, the involvement of $5-\mathrm{HT}_{7}$ receptors in the pro-social action of amisulpride has been recently demonstrated, and $5-\mathrm{HT}_{7}$ receptor antagonism was postulated as a possible mechanism for the treatment of social withdrawal—one of the core negative symptoms of schizophrenia [20]. Other preclinical findings, implicating the role of $5-\mathrm{HT}_{7}$ receptors in learning and memory, suggest that blockade of this receptor may be beneficial against cognitive impairments in schizophrenia [21].

Given the role of $5-\mathrm{HT}_{7}$ receptors in the mechanism of action of antidepressants and antipsychotics, various groups of ligands have been developed but attributed mainly with linear arrangement of basic pharmacophore features that include long chain arylpiperazine structure [22,23]. Looking for new leads with different pattern of potential ligand-5- $\mathrm{HT}_{7}$ receptor interactions, we screened our in-house compound library and high $5-\mathrm{HT}_{7} \mathrm{R}$ affinity was found for some 4-mono-, or 4,6-di-substutited 2-(4-methylpiperazino)pyrimidine derivatives, developed earlier as 5- $\mathrm{HT}_{2 \mathrm{~A}}$ antagonists [24]. Here we present synthesis and extensive structure-5- $\mathrm{HT}_{7}$ receptor affinity study on piperazin-1-yl substituted unfused heterobiaryls and related compounds.

\section{Results}

\subsection{Chemistry}

The commercially available substituted pyrimidines, quinazolines, pyridines and benzenes were used as starting materials in the synthesis of a novel library of $5-\mathrm{HT}_{7}$ receptor ligands. Substituted pyrimidines are the most extensive class of compounds used in this study. The general synthetic approach developed in our laboratories includes the addition reaction of an aryl(heteroaryl)lithium reagent to generate a substituted dihydropyrimidine or dihydroquinazoline intermediate product, which, without isolation, undergoes aromatization upon treatment with 2,3-dichloro-5,6-dicyano-1,4-benzoquinone (DDQ) (Schemes 1 and 2) [24,25].

Many final products were obtained by nucleophilic displacement reaction of a halogen activated by an appropriately positioned ring nitrogen atom in pyrimidines, quinazolines and pyridines (Schemes 1 and 3, Schemes 4-8). By using this methodology, 4-substituted 2-chloropyrimidine or 2-chloroquinazoline substrates were easily functionalized with amines to give the final products 1,2 , 21, 23, 24, 26, 29, 30, 32, 36-46, and 48. With 2,4-dichloropyrimidines, such nucleophilic displacement is regioselective, giving rise to 4-amino-2-chloropyrimidines, often with yields exceeding $90 \%$ [26]. In this work, the regioselective displacement reaction of 2,4-dichloro-6-(3-furyl)pyrimidine with dimethylamine at ambient temperature yielded a 2-chloro-4-dimethylamino intermediate product, the subsequent treatment of which with $N$-methylpiperazine at an elevated temperature furnished the final product 4-dimethylamino-6-(3-furyl)-2-(4-methylpiperazin-1-yl)pyrimidine (19). On the other hand, two consecutive introductions of heteroaryl groups at positions 4 and 6 of 2-chloropyrimidine followed 
by nucleophilic displacement of the 2-chloro atom yielded a variety of substituted pyrimidines 11-20, 22, 25, 27, 28, 31 (Scheme 1).

The classical alkylation and acylation reactions of $\mathbf{1}$ provided facile entry to compounds 3-10 (Scheme 2). A similar strategy afforded a piperazinium derivative 47 (see Experimental). It was also found that the conjugate addition reaction of dimethylamine with 2-chloro-4-vinylquinazoline [27,28] proceeds cleanly to furnish 2-chloro-4-(2-dimethylamino)ethyl substituted quinazoline, the subsequent treatment of which with $N$-methylpiperazine yielded the desired product 50 (Scheme 5).

The Suzuki mono-coupling reaction of a dihalogeno-substituted pyridine with a heteroarylboronic acid followed by classical nucleophilic displacement of the second halogen were used to synthesize pyridine derivatives 51-59 (Schemes 6-8). The reaction sequence depended on type of substrate used.

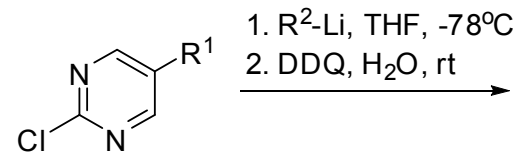

$\mathrm{R}^{1}=\mathrm{H}, n$-propyl

$\mathrm{R}^{2}, \mathrm{R}^{4}=$ alkyl, aryl, heteroaryl

For definition of the substituents, see Table 1

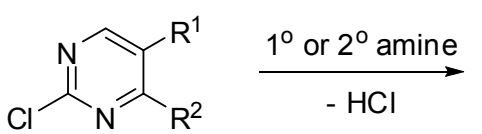

1. $\mathrm{R}^{4}-\mathrm{Li}, \mathrm{THF},-78^{\circ} \mathrm{C}$

2. $\mathrm{DDQ}, \mathrm{H}_{2} \mathrm{O}, \mathrm{rt}$<smiles>[R]c1cnc(O[Hg])nc1[R]</smiles>

$1,2,21,23,24,26$

$29,30,32,36-46$<smiles>[R]c1nc(Cl)nc([R2])c1[R]</smiles><smiles>[R]c1nc(N2CCN(C)CC2)nc([R])c1[R16]</smiles>

27, 28,31

Scheme 1. Synthesis of substituted pyrimidines 1, 2, 11-28, 36-46 (see Table 1).<smiles>[R]CC([R])([X])C</smiles><smiles>[R]N1CCN(c2nccc(-c3ccoc3)n2)CC1</smiles>

Scheme 2. Synthesis of substituted pyrimidines 3-10 and 47 (see Table 1).<smiles>Clc1ncc2ccccc2n1</smiles><smiles>Clc1nc(-c2ccoc2)c2ccccc2n1</smiles><smiles>CN1CCNCC1</smiles><smiles>C[14C]1CCN(c2nc(-c3ccoc3)c3ccccc3n2)CC1</smiles>

Scheme 3. Synthesis of quinazoline 48 .<smiles>Clc1nc(Cl)c2ccccc2n1</smiles><smiles>CN1CCNCC1</smiles><smiles>CN1CCN(c2nc(N3CCN(C)CC3)c3ccccc3n2)CC1</smiles>

Scheme 4. Synthesis of quinazoline 49. 


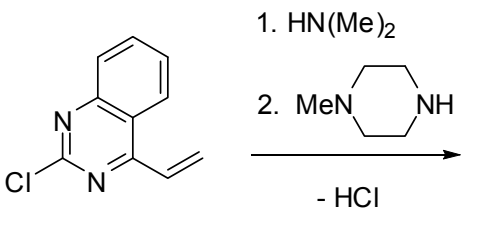<smiles>CN(C)CCc1nc(N2CCN(C)CC2)nc2ccccc12</smiles>

Scheme 5. Synthesis of quinazoline 50.<smiles>CCCc1ccnc(N2CCN(C)CC2)c1</smiles>

Scheme 6. Synthesis of substituted pyridines 51-53 (see Table 4).<smiles>Cc1cc(Br)cc(Br)n1</smiles><smiles>Cc1cc(Br)cc(N2CCN(C)CC2)n1</smiles><smiles>CCOC(=O)OB(O)O</smiles>

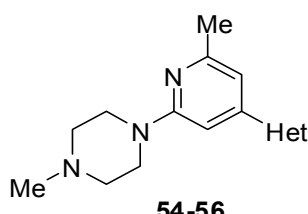

Scheme 7. Synthesis of substituted pyridines 54-56 (see Table 4).<smiles>CN1CCN(CC2CN3CCC2C3)CC1</smiles><smiles>CN1CCN(c2cccc(Br)n2)CC1</smiles><smiles>CCc1cccc(N2CCN(C)CC2)n1</smiles>

Scheme 8. Synthesis of substituted pyridines 57-59 (see Table 4).

Table 1. 5-HT 7 binding affinities of pyrimidine derivatives 1-41.

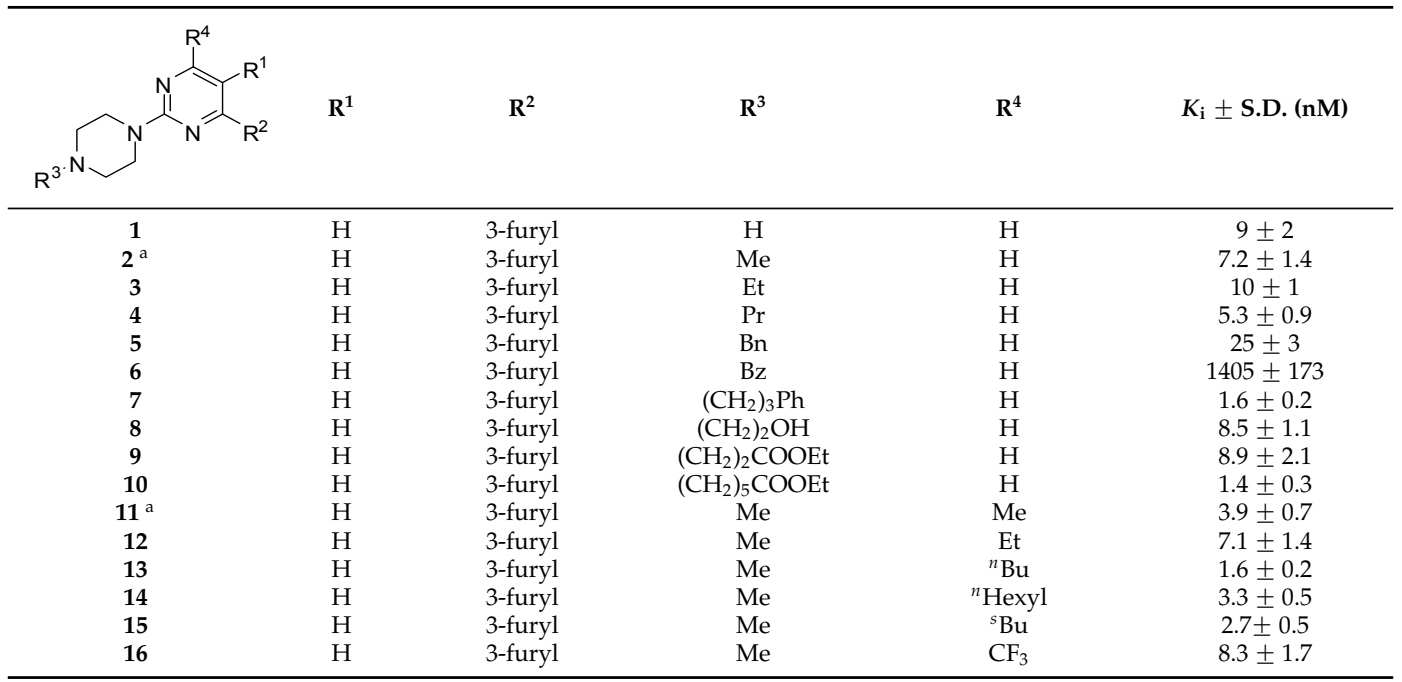


Table 1. Cont.

\begin{tabular}{|c|c|c|c|c|c|}
\hline . & $\mathbf{R}^{1}$ & $\mathbf{R}^{2}$ & $\mathbf{R}^{3}$ & $\mathbf{R}^{4}$ & $K_{\mathrm{i}} \pm$ S.D. (nM) \\
\hline 17 & $\mathrm{H}$ & 3-furyl & $\mathrm{Me}$ & & $18 \pm 3$ \\
\hline $18^{a}$ & $\mathrm{H}$ & 3-furyl & $\mathrm{Me}$ & 3-furyl & $22 \pm 2$ \\
\hline 19 & $\mathrm{H}$ & 3-furyl & $\mathrm{Me}$ & $\mathrm{N}(\mathrm{Me})_{2}$ & $>10,000$ \\
\hline 20 & $\mathrm{H}$ & 3-furyl & $\mathrm{Me}$ & $-\mathrm{N}$ & $>10,000$ \\
\hline 21 & ${ }^{n} \operatorname{Pr}$ & 3-furyl & $\mathrm{Me}$ & $\mathrm{H}$ & $1334 \pm 232$ \\
\hline 22 & ${ }^{n} \operatorname{Pr}$ & 3-furyl & $\mathrm{Me}$ & ${ }^{n} \mathrm{Bu}$ & $1250 \pm 116$ \\
\hline 23 & $\mathrm{H}$ & & $\mathrm{Me}$ & $\mathrm{H}$ & $1920 \pm 373$ \\
\hline 24 & $\mathrm{H}$ & & $\mathrm{Me}$ & $\mathrm{H}$ & $462 \pm 54$ \\
\hline 25 & $\mathrm{H}$ & & $\mathrm{Me}$ & ${ }^{n}$ hexyl & $12 \pm 2$ \\
\hline $26^{\mathrm{b}}$ & $\mathrm{H}$ & 2-furyl & $\mathrm{Me}$ & $\mathrm{H}$ & $1021 \pm 96$ \\
\hline 27 & $\mathrm{H}$ & 2-furyl & $\mathrm{Me}$ & Et & $380 \pm 44$ \\
\hline 28 & $\mathrm{H}$ & 2-furyl & $\mathrm{Me}$ & ${ }^{n} \mathrm{Bu}$ & $450 \pm 63$ \\
\hline 29 & $\mathrm{H}$ & & $\mathrm{Me}$ & $\mathrm{H}$ & $4230 \pm 680$ \\
\hline 30 & $\mathrm{H}$ & 3-thienyl & $\mathrm{Me}$ & $\mathrm{H}$ & $83 \pm 9$ \\
\hline $31^{c}$ & $\mathrm{H}$ & 3-thienyl & $\mathrm{Me}$ & ${ }^{n} \mathrm{Bu}$ & $15 \pm 3$ \\
\hline $32^{\mathrm{a}, \mathrm{b}}$ & $\mathrm{H}$ & 2-thienyl & $\mathrm{Me}$ & $\mathrm{H}$ & $480 \pm 65$ \\
\hline $33^{\mathrm{d}}$ & $\mathrm{H}$ & 2-OH- $\mathrm{C}_{6} \mathrm{H}_{4}$ & $\mathrm{Me}$ & $\mathrm{H}$ & $>10,000$ \\
\hline $34^{\mathrm{d}}$ & $\mathrm{H}$ & 3-OH- $\mathrm{C}_{6} \mathrm{H}_{4}$ & $\mathrm{Me}$ & $\mathrm{H}$ & $>10,000$ \\
\hline $35^{\mathrm{d}}$ & $\mathrm{H}$ & $4-\mathrm{OH}-\mathrm{C}_{6} \mathrm{H}_{4}$ & $\mathrm{Me}$ & $\mathrm{H}$ & $>10,000$ \\
\hline 36 & $\mathrm{H}$ & & $\mathrm{Me}$ & $\mathrm{H}$ & $7460 \pm 1230$ \\
\hline 37 & $\mathrm{H}$ & & $\mathrm{Me}$ & $\mathrm{H}$ & $5280 \pm 820$ \\
\hline 38 & $\mathrm{H}$ & & $\mathrm{Me}$ & $\mathrm{H}$ & $1530 \pm 125$ \\
\hline $39^{\mathrm{d}}$ & $\mathrm{H}$ & 3-pyr & $\mathrm{Me}$ & $\mathrm{H}$ & $780 \pm 94$ \\
\hline 40 & $\mathrm{H}$ & & $\mathrm{Me}$ & $\mathrm{H}$ & $>10,000$ \\
\hline 41 & $\mathrm{H}$ & & $\mathrm{Me}$ & $\mathrm{H}$ & $1980 \pm 275$ \\
\hline
\end{tabular}

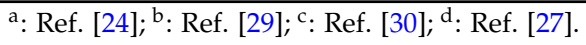

In case of benzene derivatives, Buchwald-Hartwig amination of halogeno-substituted benzenes with $N$-methylpiperazine in the presence of a palladium catalyst provided piperazine-substituted products (Scheme 9). The Suzuki condensation of these intermediate products with heteroarylboronic acids yielded the desired heteroaryl-substituted benzenes $\mathbf{6 0 - 7 1}$. It should be noted that the majority of the two-step reactions discussed above were conducted with crude intermediate products. However, the final products were rigorously characterized in all cases studied. 


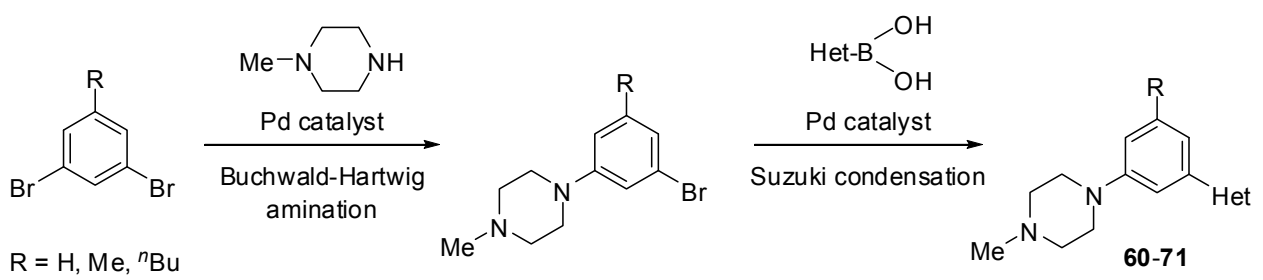

Scheme 9. Synthesis of substituted benzenes 60-71 (see Table 5).

\subsection{Pharmacology}

Novel scaffold endowed with $5-\mathrm{HT}_{7} \mathrm{R}$ activity was identified by screening of the in-house compound library in a single compound concentration of $1 \mu \mathrm{M}$ in a competition radioligand binding assay using $\left[{ }^{3} \mathrm{H}\right] 5-\mathrm{CT}$ and HEK293 cells overexpressing the human $5-\mathrm{HT}_{7 \mathrm{~b}}$ receptors. Compounds showing $>60 \%$ of inhibition, namely (4-(3-furyl)-2-(4-methylpiperazin-1-yl)pyrimidine (2) and its two derivatives 11 and 18 were further tested in full binding experiments, and, as for all the newly synthesized compounds (1, 3-10, 12-17 and 19-71), 5- $\mathrm{HT}_{7} \mathrm{R}$ affinity $\left(K_{\mathrm{i}}\right.$ values $\left.\pm \mathrm{SD}\right)$ was determined in at least two independent experiments run in triplicate [31]. The functional properties of two selected compounds 12 and 13 active on $5-\mathrm{HT}_{7} \mathrm{R}$ were further evaluated using their ability to inhibit cAMP production induced by 5-CT $(10 \mathrm{nM})$ in the same cellular system [32,33]. In addition, compounds 12 and 13 were evaluated for their affinity at three other serotonergic receptors: 5- $\mathrm{HT}_{1 \mathrm{~A}}, 5-\mathrm{HT}_{2 \mathrm{~A}}, 5-\mathrm{HT}_{6}$ and dopaminergic $\mathrm{D}_{2}$ in standard competition binding assays by use of the appropriate radioligand: [ $\left.{ }^{3} \mathrm{H}\right]-8-O H-D P A T ~(187 \mathrm{Ci} / \mathrm{mmol}),\left[{ }^{3} \mathrm{H}\right]-K e t a n s e r i n ~(66.9 \mathrm{Ci} / \mathrm{mmol}),\left[{ }^{3} \mathrm{H}\right]-\mathrm{LSD}(85.2 \mathrm{Ci} / \mathrm{mmol})$ and $\left[{ }^{3} \mathrm{H}\right]$-Raclopride $(74.4 \mathrm{Ci} / \mathrm{mmol})$, respectively, and cell line with overexpressed receptor $(\mathrm{CHO}$ for 5- $\mathrm{HT}_{2 \mathrm{~A}}$ and HEK293 for all the others) [33,34].

\section{Discussion}

The objective of this study was to determine which combinations of structural features affect the $5-\mathrm{HT}_{7}$ binding affinity of unfused heterobiaryls. The intended SAR studies included synthesis of new analogs of the model compound 2 and encompassed the following points: (1) substitution of the amino group within the piperazine ring; (2) introduction of alkyl, amino and bulky substituents into positions $4 / 6$ and/or 5 of the pyrimidine ring; (3) modifications of the heteroaryl group in position 4/6 of the pyrimidine; (4) replacement of the piperazinyl group by other amino substituents; and (5) synthesis of a series of pyridines and benzenes allowing comparison of the influence of the central ring nitrogen atom(s) on the ligand affinity.

First, investigating the influence of substituents at the basic piperazine atom, it was found that unsubstituted (1), simple alkyls (3 and 4), arylalkyl (7), hydroxyalkyl (8) or even esters (9 and 10) provide a similar level of $5-\mathrm{HT}_{7} \mathrm{R}$ affinity $\left(K_{\mathrm{i}}=1.4-10 \mathrm{nM}\right)$ as methylated hit compound $2\left(K_{\mathrm{i}}=7.2 \mathrm{nM}\right)$. Slight decrease in $5-\mathrm{HT}_{7} \mathrm{R}$ affinity is observed for benzyl derivative $5\left(K_{\mathrm{i}}=25 \mathrm{nM}\right)$ which is probably caused by a negative steric influence of the phenyl group on the key interaction between a protonated nitrogen and aspartic acid (D3.32) residue in the receptor [35]. Moreover, with the benzoyl group (6), there is an obvious negative effect on the affinity $\left(K_{i}=1405 \mathrm{nM}\right)$ that arises from diminished basicity of the piperazine nitrogen atom (Table 1 ).

In the literature, piperazine has been often a key element of $5-\mathrm{HT}_{7} \mathrm{R}$ ligands [22], and it is also optimal for heterobiaryl compounds, as its replacement results in decreased affinity (Table 2). Indeed, introduction of homopiperazine leads to ligand with a moderate affinity for $5-\mathrm{HT}_{7} \mathrm{R}\left(42, K_{\mathrm{i}}=148 \mathrm{nM}\right)$, whereas no affinity is observed for piperidine (43) and morpholine (44) derivatives that lack a basic nitrogen atom. In the group of compounds incorporating sterically hindered amines (45-47), only the ligand with positively charged quaternary nitrogen atom displayed moderate $5-\mathrm{HT}_{7} \mathrm{R}$ affinity (47, $\left.K_{\mathrm{i}}=299 \mathrm{nM}\right)$. 
Table 2. Affinities of pyrimidines $\mathbf{4 2}-\mathbf{4 7}$ for $5-\mathrm{HT}_{7}$ receptor.

(1)

Further modifications of the model compound 2 involved introductions of substituents at position 6 of the pyrimidine ring. Alkyl groups (11-16) are very well tolerated in terms of $5-\mathrm{HT}_{7}$ receptors affinity ( $K_{\mathrm{i}}$ values in the range of 1.6 to $8.3 \mathrm{nM}$ ), while introduction of bulky cyclohexenylethynyl (17) and 3-furyl (18) groups results only in a minor reduction of the binding affinity with the $K_{\mathrm{i}}$ values of 18 and $22 \mathrm{nM}$, respectively. It can be seen, however, that amino groups $(\mathbf{1 9}, \mathbf{2 0})$ at position 6 and alkyl substituents at position $5(\mathbf{2 1}, \mathbf{2 2})$ are highly detrimental for the affinity.

Next, the SAR analysis of the substituents at position 4 of the pyrimidine ring was investigated by modifications and replacement of the 3-furyl group. Compounds 23, 24 with methyl substituents within the 3-furyl ring display reduced affinities ( $K_{\mathrm{i}}$ values of 1,920 and $462 \mathrm{nM}$, respectively). Interestingly, introduction of an $n$-hexyl group (25) at position 6 of the pyrimidine in compound 24 restores high affinity for $5-\mathrm{HT}_{7} \mathrm{R}\left(K_{\mathrm{i}}=12 \mathrm{nM}\right)$. A similar trend can be recognized for less active ligands 26 (2-furyl, $K_{\mathrm{i}}=1,021 \mathrm{nM}$ ) and 30 (3-thienyl, $K_{\mathrm{i}}=83 \mathrm{nM}$ ), where addition of a 6-alkyl substituent results in a 2- or 3 -fold boost in affinity (ethyl, 27, $K_{\mathrm{i}}=380 \mathrm{nM}$; $n$-butyl, 28, $K_{\mathrm{i}}=450 \mathrm{nM}$ and $n$-butyl, 31, $K_{\mathrm{i}}=15 \mathrm{nM}$ ). As a general rule, 3-furyl $(2,24)$ and 3-thienyl (30) derivatives are 5 to 140 -fold more active than their 2-furyl $(\mathbf{2 6}, \mathbf{2 9})$ and 2-thienyl (32) counterparts. Replacement of the 3-furyl group for $o-, m-$, p-hydroxyphenyl (33-35), pyridin-3-yl (39), thiazol-2-yl (40) or imidazol-1-yl (41) group as well as benzo-fused heterocyclic (36-38) moieties does not furnish ligands with noteworthy affinity for $5-\mathrm{HT}_{7} \mathrm{R}$ $\left(K_{\mathrm{i}}>1000 \mathrm{nM}\right)$. Thus, it appears that the 3-furyl group is necessary for a high affinity of $5-\mathrm{HT}_{7} \mathrm{R}$ ligands or, alternatively, a 3-thienyl moiety but with an appropriate enhancing substitutent at position 6 of the pyrimidine ring (Table 1 ).

Next it was found that quinazoline derivatives (48-50), which can be treated as 5,6-disubstituted pyrimidine analogs, were inactive $\left(K_{\mathrm{i}}>1910 \mathrm{nM}\right)$. This result is fully consistent with our finding that substitution at position 5 is highly detrimental for $5-\mathrm{HT}_{7} \mathrm{R}$ affinity (Table 3 ). 
Table 3. Affinities of substituted quinazolines $\mathbf{4 8 - 5 0}$ for $5-\mathrm{HT}_{7}$ receptor.

\begin{tabular}{|c|c|c|}
\hline & $\mathbf{R}$ & $K_{\mathrm{i}} \pm \mathrm{SD}(\mathrm{nM})$ \\
\hline 48 & 3-furyl & $1910 \pm 235$ \\
\hline 49 & $\mathrm{~N}-\mathrm{Me}$ & $7540 \pm 1140$ \\
\hline 50 & $\left(\mathrm{CH}_{2}\right)_{2} \mathrm{~N}(\mathrm{Me})_{2}$ & $>10,000$ \\
\hline
\end{tabular}

Having established reasonable SAR around pyrimidine central ring, we focused our attention on the role of the pyrimidine core itself, analyzing a series of substituted pyridine- and phenyl-piperazine analogs. The pyridine derivatives (51-59) were then synthesized to determine whether both nitrogen atoms within the central heterocycle are needed for the ligand to retain affinity for the binding pocket of the receptor (Table 4). The biological data show that both isomeric 4-(3-furyl) (51) and 6-(3-furyl) (57) pyridine ligands still demonstrate high affinities for the $5-\mathrm{HT}_{7} \mathrm{R}\left(K_{\mathrm{i}}=17 \mathrm{nM}\right.$ and $8 \mathrm{nM}$, respectively). However, for the 2-furyl derivatives, position $4\left(52 K_{\mathrm{i}}=307 \mathrm{nM}\right)$ is preferred over position $6\left(59 K_{\mathrm{i}}=1135 \mathrm{nM}\right)$ of the pyridine as the attachment site. The pyridine ligands incorporating 3-thienyl ( $\left.58 K_{\mathrm{i}}=79 \mathrm{nM}\right)$ and 2-thienyl $\left(53 K_{\mathrm{i}}=396 \mathrm{nM}\right)$ substituents are nearly equipotent compared to their pyrimidine counterparts $\left(30, K_{\mathrm{i}}=83 \mathrm{nM}\right.$ and $\left.32, K_{\mathrm{i}}=480 \mathrm{nM}\right)$. Similarly to pyrimidine ligands, introduction of an alkyl substituent into position 6 of the pyridine ring results in 2- or 3-fold boost in affinity $\left(54 K_{\mathrm{i}}=8 \mathrm{nM} ; 55 K_{\mathrm{i}}=139 \mathrm{nM}\right.$ and $56 K_{\mathrm{i}}=117 \mathrm{nM}$ vs 51, $K_{\mathrm{i}}=17 \mathrm{nM} ; \mathbf{5 2} K_{\mathrm{i}}=307 \mathrm{nM}$ and $53 K_{\mathrm{i}}=396 \mathrm{nM}$, respectively).

Table 4. Binding affinities of substituted pyridines 51-59 for 5- $\mathrm{HT}_{7}$ receptor (see Schemes 6-8).

\begin{tabular}{cccccc}
\hline & & & & \\
\\
$5 \mathbf{5 1}$ & $\mathrm{H}$ & 3-furyl & $\mathrm{N}$ & $\mathrm{CH}$ & $17 \pm 2$ \\
$\mathbf{5 2}$ & $\mathrm{H}$ & 2-furyl & $\mathrm{N}$ & $\mathrm{CH}$ & $307 \pm 42$ \\
$\mathbf{5 3}$ & $\mathrm{H}$ & 2-thienyl & $\mathrm{N}$ & $\mathrm{CH}$ & $396 \pm 55$ \\
$\mathbf{5 4}$ & $\mathrm{Me}$ & 3-furyl & $\mathrm{N}$ & $\mathrm{CH}$ & $8 \pm 1$ \\
$\mathbf{5 5}$ & $\mathrm{Me}$ & 2-furyl & $\mathrm{N}$ & $\mathrm{CH}$ & $139 \pm 22$ \\
$\mathbf{5 6}$ & $\mathrm{Me}$ & 2-thienyl & $\mathrm{N}$ & $\mathrm{CH}$ & $117 \pm 12$ \\
$\mathbf{5 7}$ & $\mathrm{H}$ & 3-furyl & $\mathrm{CH}$ & $\mathrm{N}$ & $11 \pm 2$ \\
$\mathbf{5 8}$ & $\mathrm{H}$ & 3-thienyl & $\mathrm{CH}$ & $\mathrm{N}$ & $79 \pm 14$ \\
$\mathbf{5 9}$ & $\mathrm{H}$ & 2-furyl & $\mathrm{CH}$ & $\mathrm{N}$ & $1135 \pm 154$ \\
\hline
\end{tabular}

After finding that the pyrimidine core can be safely replaced with a pyridine ring, our attention was turned to compounds devoid of any nitrogen atoms within the central moiety of a ligand (Table 5). 3-Furyl $\left(60, K_{\mathrm{i}}=31 \mathrm{nM}\right)$ and 3-thienyl $\left(66, K_{\mathrm{i}}=342 \mathrm{nM}\right)$ benzene analogs show significant 5- $\mathrm{HT}_{7} \mathrm{R}$ affinities, although they are 2- and 4-fold less active than their pyrimidine and pyridine equivalents. $5-\mathrm{HT}_{7} \mathrm{R}$ affinities of 2-furyl $\left(63, K_{\mathrm{i}}=914 \mathrm{nM}\right)$ and 2-thienyl $\left(69, K_{\mathrm{i}}=542 \mathrm{nM}\right)$ derivatives remain at moderate levels. Consequently, introduction of methyl groups into position 5 of 1,3-disubstituted benzene analogs results in 2- to 7-fold increases of the binding properties $\left(64, K_{\mathrm{i}}=312 \mathrm{nM} ; 67\right.$, $K_{\mathrm{i}}=47 \mathrm{nM}$ and 70, $\left.K_{\mathrm{i}}=297 \mathrm{nM}\right)$, except for the 3-furyl ligand $\left(61, K_{\mathrm{i}}=37 \mathrm{nM}\right)$ which stays equipotent to its unsubstituted counterpart. Surprisingly, the $n$-butyl substituted benzene derivatives are lower 
in 5- $\mathrm{HT}_{7} \mathrm{R}$ affinity $\left(62, K_{\mathrm{i}}=106 \mathrm{nM} ; 65, K_{\mathrm{i}}=743 \mathrm{nM} ; 68, K_{\mathrm{i}}=263 \mathrm{nM}\right.$ and 71, $\left.K_{\mathrm{i}}=734 \mathrm{nM}\right)$. The observed phenomenon may arise from higher lipophilicity of the ligands, which increases non-specific interactions with the tested $5-\mathrm{HT}_{7}$ receptor.

Table 5. Binding affinities of substituted benzenes $\mathbf{6 0 - 7 1}$ for $5-\mathrm{HT}_{7}$ receptor.

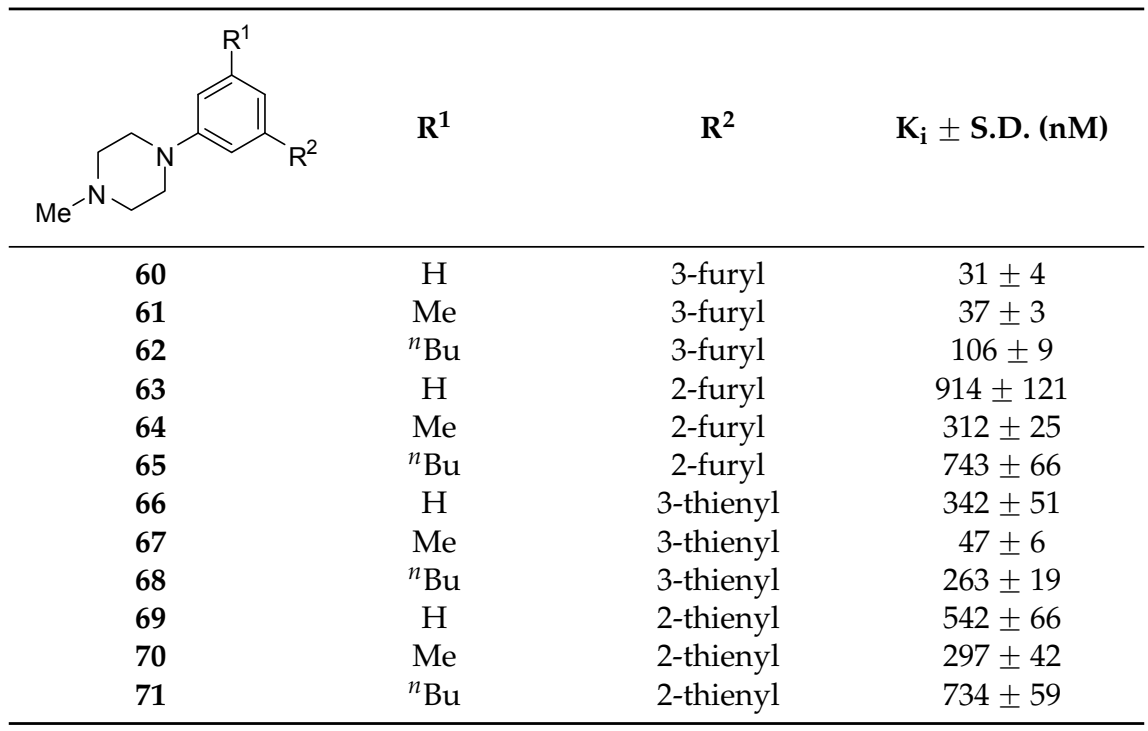

Two selected compounds $\mathbf{1 2}$ and $\mathbf{1 3}$ with high $5-\mathrm{HT}_{7} \mathrm{R}$ affinity were next evaluated in in vitro functional cAMP assay (Figure 1$)$ and their selectivity for other serotonin $\left(5-\mathrm{HT}_{1 \mathrm{~A}}, 5-\mathrm{HT}_{2 \mathrm{~A}}, 5-\mathrm{HT}_{6}\right)$ and dopamine $\mathrm{D}_{2}$ receptors was investigated (Table 6). It was found that both $\mathbf{1 2}$ and 13, similarly to (2R)-1-((3-hydroxyphenyl)sulfonyl)-2-(2-(4-methyl-1-piperidinyl)ethyl)pyrrolidine (SB-269970) [32]—a selective 5-HT7R antagonist used as a control, dose-dependently decrease 5-CT-induced cAMP accumulation in transfected HEK cells expressing $5-\mathrm{HT}_{7} \mathrm{R}$ (Figure 1). It has to be stressed, however, that $5-\mathrm{HT}_{7} \mathrm{R}$ antagonistic properties of $\mathbf{1 2}$ and $\mathbf{1 3}$ are weaker $\left(K_{\mathrm{B}}=12\right.$ and $60 \mathrm{nM}$, respectively) than that of SB-269970 $\left(K_{\mathrm{B}}=1.9 \mathrm{nM}\right)$ and that, unexpectedly, $n$-butyl derivative 13, despite showing higher affinity, is less potent $5-\mathrm{HT}_{7} \mathrm{R}$ antagonist than ethyl analog 12. Alkyl substituent at position 4 also influences selectivity profile-both compounds show almost the same, high affinity for $5-\mathrm{HT}_{2 \mathrm{~A}} \mathrm{R}$ ( $K_{\mathrm{i}}=10$ and $12 \mathrm{nM}$ for 12 and 13, respectively) but $n$-butyl derivative is 10 - and 13-fold more active than 12 at $5-\mathrm{HT}_{6}$ and $\mathrm{D}_{2}$ receptors. Both analogs are weak $5-\mathrm{HT}_{1 \mathrm{~A}} \mathrm{R}$ binders.

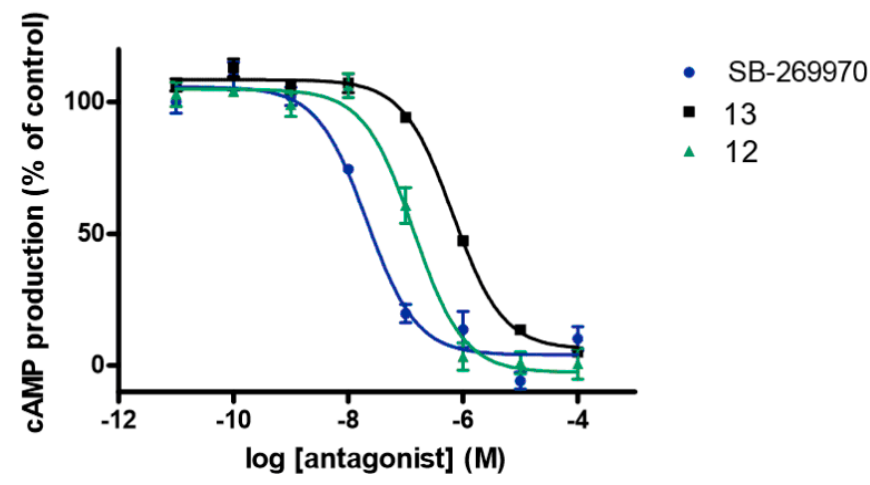

Figure 1. The functional properties of compounds $\mathbf{1 2}$ and $\mathbf{1 3}$ and a reference antagonist SB-269970 on $5-\mathrm{HT}_{7} \mathrm{R}$ evaluated using their ability to inhibit cAMP production induced by 5-CT (10 nM) in HEK-293 cells expressing $5-\mathrm{HT}_{7} \mathrm{R}$. 
Table 6. Extended results for compounds $\mathbf{1 2}$ and 13.

\begin{tabular}{|c|c|c|c|c|c|}
\hline & \multicolumn{5}{|c|}{$K_{\mathrm{i}} \pm$ S.D. $(\mathrm{nM})$} \\
\hline & $\mathrm{D}_{2}$ & $5-\mathrm{HT}_{1 \mathrm{~A}}$ & $5-\mathrm{HT}_{2 \mathrm{~A}}$ & $5-\mathrm{HT}_{6}$ & $5-\mathrm{HT}_{7}$ \\
\hline 12 & $466 \pm 39$ & $1501 \pm 164$ & $12 \pm 2$ & $121 \pm 14$ & $7.1 \pm 1.4$ \\
\hline 13 & $37 \pm 4$ & $637 \pm 53$ & $10 \pm 1$ & $12 \pm 2$ & $1.6 \pm 0.2$ \\
\hline
\end{tabular}

\section{Materials and Methods}

\subsection{General Methods}

All air-sensitive reactions were conducted under a nitrogen atmosphere. Tetrahydrofuran (THF) was distilled from sodium benzophenone ketyl immediately before use. Heteroaryllithium reagents were generated by direct lithiation of a heterocyclic substrate or by a bromine-lithium exchange reaction as previously reported [28] Final products were purified on a chromatotron using silica gel-coated rotors. Oily products were transformed into hydrobromide salts by using a general procedure [30] and the salts were crystallized from 95\% ethanol. Melting points (Pyrex capillary) are not corrected. The ${ }^{1} \mathrm{H}-\mathrm{NMR}(400 \mathrm{MHz})$ and ${ }^{13} \mathrm{C}-\mathrm{NMR}(100 \mathrm{MHz})$ spectra of free bases and hydrobromide salts were obtained in $\mathrm{CDCl}_{3}$ and DMSO- $d_{6}$, respectively. Mass spectra were recorded using electrospray ionization in a positive ion mode.

\subsection{Synthesis of Substituted Pyrimidines 1, 2, 21, 23, 24, 26, 29, 30, 32, 36-46 and Quinazoline 48}

A solution of the corresponding lithium reagent $(10 \mathrm{mmol})$ in THF $(10 \mathrm{~mL})$ was stirred at $-50{ }^{\circ} \mathrm{C}$ and treated dropwise with a solution of 2-chloropyrimidine, 2-chloro-5-propylpyrimidine or 2-chloroquinazoline $(12 \mathrm{mmol})$ in THF $(15 \mathrm{~mL})$. The mixture was allowed to reach $0{ }^{\circ} \mathrm{C}$ within $2 \mathrm{~h}$, then quenched with a solution of water in $\operatorname{THF}(1: 5,6 \mathrm{~mL})$, stirred at $0^{\circ} \mathrm{C}$ and treated with a solution of DDQ $(2.3 \mathrm{~g}, 10 \mathrm{mmol})$ in THF $(5 \mathrm{~mL})$. After stirring for an additional $10 \mathrm{~min}$ at $0^{\circ} \mathrm{C}$, the mixture was treated with a cold solution of sodium hydroxide $(4 \mathrm{M}, 5 \mathrm{~mL}, 20 \mathrm{mmol})$, stirred and extracted immediately with ether/hexanes $(1: 1,3 \times 10 \mathrm{~mL})$. The combined extracts were dried with anhydrous sodium sulfate, decolorized by filtration through a pad of silica gel $(5 \mathrm{~g})$ and concentrated on a rotary evaporator. The resultant crude 4-substituted 2-chloropyrimidine or 2-chloroquinazoline was treated with a primary or secondary amine $(30 \mathrm{mmol})$ in toluene $(20 \mathrm{~mL})$ in the presence of anhydrous potassium carbonate and the mixture was heated at $75^{\circ} \mathrm{C}$ for $5-10 \mathrm{~h}$, after which time a TLC analysis on silica gel eluting with ether/triethylamine (9:1) showed the absence of the substrate. Preparative chromatography was conducted eluting with ether/triethylamine/hexanes (9:5:5) to give product 1, 2, 21, 23, 24, 26, 29, 30, 32, 36-46 (Scheme 1) and 48 (Scheme 2).

\subsection{Synthesis of Polysubstituted Pyrimidines 11-20, 22, 25, 27, 28, 31}

Alternatively, the crude 4-substituted 2-chloropyrimidine, obtained as described above, was treated with a lithium reagent followed by aromatization with DDQ of the intermediate dihydropyrimidine under the conditions described above and the resultant crude 4,6-disubstituted 2-chloropyrimidine was allowed to react with $N$-methylpiperazine, as described above, to yield 4,6-disubstituted 2-( $N$-methylpiperazine-1-yl)pyrimidine 11-20, 22, 25, 27, 28, 31 (Scheme 1).

\subsection{Synthesis of [N-Substituted 2-(Piperazin-1-yl)]pyrimidines $\mathbf{3 - 1 0}$ and $\mathbf{4 7}$}

In the preparation of compounds 3-10, a mixture of 4-(3-furyl)-2-(piperazin-1-yl)pyrimidine $(\mathbf{1}, 200 \mathrm{mg}, 0.87 \mathrm{mmol})$, synthesized as described above, and anhydrous potassium carbonate $(300 \mathrm{mg}$, $2.2 \mathrm{mmol})$ in anhydrous acetonitrile $(10 \mathrm{~mL})$ was stirred at $-10^{\circ} \mathrm{C}$ and treated with ethyl bromide, propyl bromide, benzyl chloride, benzoyl chloride, 3-phenylpropyl bromide, 2-bromoethanol, ethyl 3-bromopropionate or ethyl 6-bromohexanoate $(2.0 \mathrm{mmol})$ (Scheme 2$)$. The mixture was stirred at $23^{\circ} \mathrm{C}$ for $2 \mathrm{~h}$ and then quenched with water $(2 \mathrm{~mL})$ and extracted with ether $(3 \times 20 \mathrm{~mL})$. The extract was 
dried with anhydrous sodium sulfate and concentrated. Purification by chromatography eluting with dichloromethane/methanol (10:1) gave product 3-10.

In the preparation of 4-[4-(3-furyl)pyrimidin-2-yl]piperazine-1-spiro-1-morpholinium iodide (47), a mixture of compound $1(1 \mathrm{mmol}), 1$-iodo-2-(2-iodoethoxy)ethane $(1 \mathrm{mmol})$ and anhydrous potassium carbonate $(140 \mathrm{mg}, 1 \mathrm{mmol})$ in anhydrous acetonitrile $(10 \mathrm{~mL})$ was heated under reflux for $1 \mathrm{~h}$ and then quenched with water $(5 \mathrm{~mL})$. Product 47 was extracted with ethyl acetate and purified on a chromatotron eluting with dichloromethane/methanol (8:2).

4-(3-Furyl)-2-(piperazin-1-yl)pyrimidine (1). Yield 70\% (free base); an oil; ${ }^{1} \mathrm{H}-\mathrm{NMR}: \delta 8.33$ (d, $J=5.1 \mathrm{~Hz}$, $1 \mathrm{H}), 8.10(\mathrm{~s}, 1 \mathrm{H}), 7.51(\mathrm{~m}, 1 \mathrm{H}), 6.89(\mathrm{~m}, 1 \mathrm{H}), 6.67(\mathrm{~d}, J=5.1 \mathrm{~Hz}, 1 \mathrm{H}), 3.88(\mathrm{~m}, 4 \mathrm{H}), 2.98(\mathrm{~m}, 4 \mathrm{H})$. A hydrobromide salt: m.p. $241-242{ }^{\circ} \mathrm{C}$. Anal. Calcd for $\mathrm{C}_{12} \mathrm{H}_{14} \mathrm{~N}_{4} \mathrm{O}_{2} \bullet \mathrm{HBr} \bullet 0.5 \mathrm{H}_{2} \mathrm{O}: \mathrm{C}, 45.01 ; \mathrm{H}, 5.03$; $\mathrm{N}, 17.50$. Found: $\mathrm{C}, 44.82 ; \mathrm{H}, 4.85 ; \mathrm{N}, 17.39$.

\section{4-(3-Furyl)-2-(4-methylpiperazin-1-yl)pyrimidine (2) [24].}

2-(4-Ethylpiperazin-1-yl)-4-(3-furyl)pyrimidine (3). Yield 61\% (free base); an oil; ${ }^{1} \mathrm{H}-\mathrm{NMR}: \delta 8.29$ (d, $J=5.1 \mathrm{~Hz}, 1 \mathrm{H}), 8.07(\mathrm{~m}, 1 \mathrm{H}), 7.48(\mathrm{~m}, 1 \mathrm{H}), 6.86(\mathrm{~m}, 1 \mathrm{H}), 6.63(\mathrm{~d}, J=5.1 \mathrm{~Hz}, 1 \mathrm{H}), 3.91(\mathrm{~m}, 4 \mathrm{H}), 2.53(\mathrm{~m}$, $4 \mathrm{H}), 2.49(\mathrm{q}, J=7.2 \mathrm{~Hz}, 2 \mathrm{H}), 1.14(\mathrm{t}, J=7.2 \mathrm{~Hz}, 3 \mathrm{H})$. A hydrobromide salt. Anal. Calcd for $\mathrm{C}_{14} \mathrm{H}_{18} \mathrm{~N}_{4} \mathrm{O} \cdot 2$ $\mathrm{HBr} \bullet 0.5 \mathrm{H}_{2} \mathrm{O}: \mathrm{C}, 39.18 ; \mathrm{H}, 4.93 ; \mathrm{N}, 13.06$. Found: $\mathrm{C}, 39.29 ; \mathrm{H}, 4.36 ; \mathrm{N}, 12.81$.

4-(3-Furyl)-2-(4-propylpiperazin-1-yl)pyrimidine (4). Yield 39\% (free base); an oil; ${ }^{1} \mathrm{H}-\mathrm{NMR}$ : $\delta 8.29$ (d, $J=5.1 \mathrm{~Hz}, 1 \mathrm{H}), 8.06(\mathrm{~s}, 1 \mathrm{H}), 7.48(\mathrm{~s}, 1 \mathrm{H}), 6.86(\mathrm{~s}, 1 \mathrm{H}), 6.63(\mathrm{~d}, J=5.1 \mathrm{~Hz}, 1 \mathrm{H}), 3.90(\mathrm{t}, 4 \mathrm{H}), 2.52(\mathrm{~m}, 4 \mathrm{H})$, $2.36(\mathrm{t}, J=7.4 \mathrm{~Hz}, 2 \mathrm{H}), 1.57(\mathrm{~m}, 2 \mathrm{H}), 0.94(\mathrm{t}, J=7.4 \mathrm{~Hz}, 3 \mathrm{H})$. A hydrobromide salt: m.p. $274-277^{\circ} \mathrm{C}$. Anal. Calcd for $\mathrm{C}_{15} \mathrm{H}_{20} \mathrm{~N}_{4} \mathrm{O} \bullet 2 \mathrm{HBr} \bullet \mathrm{H}_{2} \mathrm{O}: \mathrm{C}, 39.84 ; \mathrm{H}, 5.35 ; \mathrm{N}, 12.39$. Found: $\mathrm{C}, 40.39 ; \mathrm{H}, 4.84 ; \mathrm{N}, 12.45$.

2-(4-Benzylpiperazin-1-yl)-4-(3-furyl)pyrimidine (5). Yield 73\% (free base); an oil; ${ }^{1} \mathrm{H}-\mathrm{NMR}$ : $\delta 8.28$ (d, $J=5.1 \mathrm{~Hz}, 1 \mathrm{H}), 8.05(\mathrm{~m}, 1 \mathrm{H}), 7.47(\mathrm{~m}, 1 \mathrm{H}), 7.31(\mathrm{~m}, 5 \mathrm{H}), 6.85(\mathrm{~s}, 1 \mathrm{H}), 6.62(\mathrm{~d}, J=5.1 \mathrm{~Hz}, 1 \mathrm{H}), 3.89(\mathrm{~m}, 4 \mathrm{H})$, $3.57(\mathrm{~s}, 2 \mathrm{H}), 2.53(\mathrm{~m}, 4 \mathrm{H})$. A hydrobromide salt: m.p. $>280^{\circ} \mathrm{C}$. Anal. Calcd for $\mathrm{C}_{19} \mathrm{H}_{20} \mathrm{~N}_{4} \mathrm{O} \bullet 2 \mathrm{HBr} \bullet \mathrm{H}_{2} \mathrm{O}$ : C, 45.62; H, 4.84; N, 11.20. Found: C, 45.93; H, 4.67; N, 11.11.

2-(4-Benzoylpiperazin-1-yl)-4-(3-furyl)pyrimidine (6). Yield 33\% (free base); an oil; ${ }^{1} \mathrm{H}-\mathrm{NMR}$ : $\delta 8.31$ (d, $J=5.1 \mathrm{~Hz}, 1 \mathrm{H}), 8.06(\mathrm{~m}, 1 \mathrm{H}), 7.48(\mathrm{~m}, 1 \mathrm{H}), 7.44(\mathrm{~m}, 5 \mathrm{H}), 6.85(\mathrm{~m}, 1 \mathrm{H}), 6.69(\mathrm{~d}, J=5.1 \mathrm{~Hz}, 1 \mathrm{H}), 4.27$ (broad m, 8H); ${ }^{13}$ C-NMR: $\delta$ 170.6, 161.7, 159.2, 158.13, 144.0, 143.1, 135.8, 129.8, 128.6, 127.1, 126.0, 108.5, 106.3, 44.0, 42.3. A hydrobromide salt: m.p. $221^{\circ} \mathrm{C}$ (dec.). Anal. Calcd for $\mathrm{C}_{19} \mathrm{H}_{18} \mathrm{~N}_{4} \mathrm{O}_{2} \bullet \mathrm{HBr} \bullet 0.5 \mathrm{H}_{2} \mathrm{O}$ : C, 53.79; H, 4.75; N, 13.20. Found: C, 53.97; H, 4.32; N, 13.15 .

4-(3-Furyl)-2-[(4-(3-phenylpropyl)piperazin-1-yl]pyrimidine (7). Yield 44\% (free base); an oil; ${ }^{1} \mathrm{H}-\mathrm{NMR}$ : $\delta 8.27(\mathrm{~d}, J=5 \mathrm{~Hz}, 1 \mathrm{H}), 8.05(\mathrm{~s}, 1 \mathrm{H}), 7.46(\mathrm{t}, J=2 \mathrm{~Hz}, 1 \mathrm{H}), 7.27(\mathrm{dd}, J=8 \mathrm{~Hz}$ and $15 \mathrm{~Hz}, 2 \mathrm{H}), 7.18(\mathrm{~m}, 3 \mathrm{H})$, $6.85(\mathrm{t}, J=2 \mathrm{~Hz}, 1 \mathrm{H}), 6.61(\mathrm{~d}, J=5 \mathrm{~Hz}, 1 \mathrm{H}), 3.88(\mathrm{t}, J=5 \mathrm{~Hz}, 4 \mathrm{H}), 2.67(\mathrm{t}, J=8 \mathrm{~Hz}, 2 \mathrm{H}), 2.50(\mathrm{t}, J=5 \mathrm{~Hz}$, $4 \mathrm{H}), 2.41(\mathrm{t}, J=7 \mathrm{~Hz}, 2 \mathrm{H}),{ }^{13} \mathrm{C}-\mathrm{NMR}: \delta 161,8,159.0,158.0,143.8,143.0,142.1,128.4,128.3,126.2,125.7$, 108.5, 105.6, 58.1, 53.1, 43.7, 33.7, 28.5. HR-MS (ESI). Calcd for $\mathrm{C}_{21} \mathrm{H}_{25} \mathrm{~N}_{4} \mathrm{O}\left(\mathrm{M}^{+}+1\right): m / z$ 349.2028. Found: $m / z 349.2022$.

2-[4-(2-Hydroxyethyl)piperazin-1-yl]-4-(3-furyl)pyrimidine (8). Yield 58\% (free base); an oil; ${ }^{1} \mathrm{H}-\mathrm{NMR}$ : $\delta 8.34(\mathrm{t}, J=4.8 \mathrm{~Hz}, 1 \mathrm{H}), 8.27(\mathrm{~d}, J=5.2 \mathrm{~Hz}, 1 \mathrm{H}), 7.47(\mathrm{~d}, J=1.2 \mathrm{~Hz}, 1 \mathrm{H}), 6.85(\mathrm{~s}, 1 \mathrm{H}), 6.62(\mathrm{~d}, J=5.2 \mathrm{~Hz}$, $1 \mathrm{H}), 3.89(\mathrm{t}, J=4.8 \mathrm{~Hz}, 4 \mathrm{H}), 3.68(\mathrm{t}, J=5.2 \mathrm{~Hz}, 2 \mathrm{H}), 3.20\left(\right.$ broad s, exchangeable with $\left.\mathrm{D}_{2} \mathrm{O}, 1 \mathrm{H}\right), 2.58$ (m, 6H); ${ }^{13}$ C-NMR: $\delta 161.9,159.2,158.2,143.3,143.1,126.3,108.7,105.9,59.8,58.0,53.0,43.8$. HR-MS (ESI). Calcd for $\mathrm{C}_{14} \mathrm{H}_{19} \mathrm{~N}_{4} \mathrm{O}_{2}\left(\mathrm{M}^{+}+1\right): m / z$ 275.1508. Found: $m / z$ 275.1508. A hydrobromide salt: m.p. $>280{ }^{\circ} \mathrm{C}$. Anal. Calcd for $\mathrm{C}_{14} \mathrm{H}_{19} \mathrm{~N}_{4} \mathrm{O}_{2} \bullet 2 \mathrm{HBr} \bullet \mathrm{H}_{2} \mathrm{O}: \mathrm{C}, 37.02 ; \mathrm{H}, 4.88 ; \mathrm{N}, 12.34$. Found: $\mathrm{C}, 37.12$; $\mathrm{H}, 4.51 ; \mathrm{N}, 12.32$.

Ethyl 3-\{4-\{[4-(3-furyl)pyrimidin-2-yl]piperazin-1-yl\}\}propanoate (9). Yield 50\% (free base); an oil; ${ }^{1} \mathrm{H}-\mathrm{NMR}$ : $\delta 8.27(\mathrm{~d}, J=5 \mathrm{~Hz}, 1 \mathrm{H}), 8.06(\mathrm{~s}, 1 \mathrm{H}), 7.47(\mathrm{t}, J=2 \mathrm{~Hz}, 1 \mathrm{H}), 6.85(\mathrm{~m}, 1 \mathrm{H}), 6.62(\mathrm{~d}, J=5 \mathrm{~Hz}, 1 \mathrm{H}), 4.15(\mathrm{q}$, $J=7 \mathrm{~Hz}, 2 \mathrm{H}), 3.87(\mathrm{t}, J=5 \mathrm{~Hz}, 4 \mathrm{H}), 2.74(\mathrm{~m}, 2 \mathrm{H}), 2.54(\mathrm{~m}, 6 \mathrm{H}), 1.26(\mathrm{t}, J=7 \mathrm{~Hz}, 3 \mathrm{H}) ;{ }^{13} \mathrm{C}-\mathrm{NMR}: \delta 172.6$, 
161.9, 159.1, 158.1, 144.0, 143.1, 126.3, 108.6, 105.8, 60.6, 53.8, 53.0, 43.8, 32.5, 14.4. HR-MS (ESI). Calcd for $\mathrm{C}_{17} \mathrm{H}_{23} \mathrm{~N}_{4} \mathrm{O}_{3}\left(\mathrm{M}^{+}+1\right): m / z$ 331.1770. Found: $m / z 331.1756$.

Ethyl 3-\{4-\{[4-(3-furyl)pyrimidin-2-yl]piperazin-1-yl\}\}hexanoate (10). Yield 85\% (free base); an oil; ${ }^{1} \mathrm{H}-\mathrm{NMR}$ : $\delta 8.27(\mathrm{~d}, J=5 \mathrm{~Hz}, 1 \mathrm{H}), 8.06(\mathrm{~s}, 1 \mathrm{H}), 7.48(\mathrm{t}, J=2 \mathrm{~Hz}, 1 \mathrm{H}), 6.85(\mathrm{~m}, 1 \mathrm{H}), 6.62(\mathrm{~d}, J=5 \mathrm{~Hz}, 1 \mathrm{H}), 4.12$ $(\mathrm{q}, J=7 \mathrm{~Hz}, 2 \mathrm{H}), 3.88(\mathrm{t}, J=5 \mathrm{~Hz}, 4 \mathrm{H}), 2.50(\mathrm{~m}, 4 \mathrm{H}), 2.30(\mathrm{t}, J=8 \mathrm{~Hz}, 2 \mathrm{H}), 2.31(\mathrm{t}, J=8 \mathrm{~Hz}, 2 \mathrm{H}), 1.66$ $(\mathrm{m}, 2 \mathrm{H}), 1.56(\mathrm{~m}, 2 \mathrm{H}), 1.37(\mathrm{~m}, 2 \mathrm{H}), 1.25(\mathrm{t}, J=7 \mathrm{~Hz}, 3 \mathrm{H}) ;{ }^{13} \mathrm{C}-\mathrm{NMR}: \delta 173.7,161.7,158.9,158.0,143.8$, 143.0, 108.5, 105.6, 60.2, 58.6, 53.2, 43.6, 34.2, 27.1, 26.5, 24.9, 14.2. HR-MS (ESI). Calcd for $\mathrm{C}_{20} \mathrm{H}_{29} \mathrm{~N}_{4} \mathrm{O}_{3}$ $\left(\mathrm{M}^{+}+1\right): m / z$ 373.2240. Found: $\mathrm{m} / \mathrm{z} 373.2240$.

4-(3-Furyl)-6-methyl-2-(4-methylpiperazin-1-yl)pyrimidine (11) [24].

4-Ethyl-6-(3-furyl)-2-(4-methylpiperazin-1-yl)pyrimidine (12). Yield 67\% (free base); an oil; ${ }^{1} \mathrm{H}-\mathrm{NMR}$ : $\delta 8.06(\mathrm{~m}, 1 \mathrm{H}), 7.50(\mathrm{~m}, 1 \mathrm{H}), 6.88(\mathrm{~m}, 1 \mathrm{H}), 6.56(\mathrm{~s}, 1 \mathrm{H}), 3.94(\mathrm{~m}, 4 \mathrm{H}), 2.65(\mathrm{~d}, J=7.5 \mathrm{~Hz}, 2 \mathrm{H}), 2.51(\mathrm{~m}$, $4 \mathrm{H}), 2.38(\mathrm{~s}, 3 \mathrm{H}), 1.33(\mathrm{t}, J=7.5 \mathrm{~Hz}, 3 \mathrm{H})$. A hydrobromide salt: m.p. $287-288{ }^{\circ} \mathrm{C}$. Anal. Calcd for $\mathrm{C}_{15} \mathrm{H}_{20} \mathrm{~N}_{4} \mathrm{O} \bullet 2 \mathrm{HBr} \bullet 0.5 \mathrm{H}_{2} \mathrm{O}: \mathrm{C}, 40.47 ; \mathrm{H}, 5.66 ; \mathrm{N}, 12.58$. Found: $\mathrm{C}, 40.41 ; \mathrm{H}, 5.32 ; \mathrm{N}, 12.55$.

4-(n-Butyl)-6-(3-furyl)-2-(4-methylpiperazin-1-yl)pyrimidine (13). Yield 30\% (free base); an oil; ${ }^{1} \mathrm{H}-\mathrm{NMR}$ : $\delta 0.91(\mathrm{~m}, 3 \mathrm{H}), 1.35(\mathrm{~m}, 2 \mathrm{H}), 1.73(\mathrm{~m}, 2 \mathrm{H}), 2.35(\mathrm{~s}, 3 \mathrm{H}), 2.47(\mathrm{t}, J=5 \mathrm{~Hz}, 4 \mathrm{H}), 2.58(\mathrm{t}, J=7 \mathrm{~Hz}, 2 \mathrm{H})$, $3.90(\mathrm{t}, J=5 \mathrm{~Hz}, 4 \mathrm{H}), 6.50(\mathrm{~s}, 1 \mathrm{H}), 6.85(\mathrm{~m}, 1 \mathrm{H}), 7.46(\mathrm{~m}, 1 \mathrm{H}), 8.06(\mathrm{~m}, 1 \mathrm{H})$. A hydrobromide salt: m.p. $179-180{ }^{\circ} \mathrm{C}$. Anal. Calcd for $\mathrm{C}_{17} \mathrm{H}_{24} \mathrm{~N}_{4} \mathrm{O} \cdot 2 \mathrm{HBr} \bullet 1.5 \mathrm{H}_{2} \mathrm{O}: \mathrm{C}, 43.89 ; \mathrm{H}, 6.28 ; \mathrm{N}, 12.04$. Found: C, 43.95; H, 6.30; N, 11.96 .

4-(3-Furyl)-6-n-hexyl-2-(4-methylpiperazin-1-yl)pyrimidine (14). Yield 51\% (free base); an oil; ${ }^{1} \mathrm{H}-\mathrm{NMR}$ : $\delta 0.90(\mathrm{~m}, 3 \mathrm{H}), 1.32(\mathrm{~m}, 6 \mathrm{H}), 1.70(\mathrm{~m}, 2 \mathrm{H}), 2.34(\mathrm{~s}, 3 \mathrm{H}), 2.47(\mathrm{t}, J=5 \mathrm{~Hz}, 4 \mathrm{H}), 2.57(\mathrm{t}, J=7.5 \mathrm{~Hz}, 2 \mathrm{H})$, $3.91(\mathrm{t}, J=5 \mathrm{~Hz}, 4 \mathrm{H}), 6.51(\mathrm{~s}, 1 \mathrm{H}), 6.85(\mathrm{~m}, 1 \mathrm{H}), 7.46(\mathrm{~m}, 1 \mathrm{H}), 8.06(\mathrm{~m}, 1 \mathrm{H}) ;{ }^{13} \mathrm{C}-\mathrm{NMR}: \delta 14.1,22.6,28.5$, 29.1, 31.7, 38.1, 43.6, 46.3, 55.1, 104.6, 108.6, 126.4, 142.7, 143.7, 158.6, 162.0, 171.8. A hydrobromide salt: m.p. $230-233^{\circ} \mathrm{C}$. Anal. Calcd for $\mathrm{C}_{19} \mathrm{H}_{28} \mathrm{~N}_{4} \mathrm{O} \bullet \mathrm{HBr} \bullet 0.5 \mathrm{H}_{2} \mathrm{O}: \mathrm{C}, 54.54 ; \mathrm{H}, 7.23 ; \mathrm{N}, 13.39$. Found: C, 54.34; H, 7.06; N, 13.29 .

4-sec-Butyl-6-(3-furyl)-2-(4-methylpiperazin-1-yl)pyrimidine (15). Yield 37\% (free base); an oil; ${ }^{1} \mathrm{H}-\mathrm{NMR}$ : $\delta 0.87(\mathrm{t}, J=7.5 \mathrm{~Hz}, 3 \mathrm{H}), 1.25(\mathrm{~m}, 3 \mathrm{H}), 1.57(\mathrm{~m}, 1 \mathrm{H}), 1.76(\mathrm{~m}, 1 \mathrm{H}), 2.34(\mathrm{~s}, 3 \mathrm{H}), 2.47(\mathrm{t}, J=5 \mathrm{~Hz}), 2.57$ $(\mathrm{m}, 1 \mathrm{H}), 2.90(\mathrm{t}, J=5 \mathrm{~Hz}, 4 \mathrm{H}), 6.49(\mathrm{~s}, 1 \mathrm{H}), 6.87(\mathrm{~m}, 1 \mathrm{H}), 7.47(\mathrm{~m}, 1 \mathrm{H}), 8.06(\mathrm{~m}, 1 \mathrm{H}) ;{ }^{13} \mathrm{C}-\mathrm{NMR}: \delta 12.1$, 19.6, 29.1, 43.4, 43.7, 46.3, 55.1, 103.7, 108.6, 126.5, 142.7, 143.6, 158.6, 162.0, 175.8. A dihydrobromide salt: m.p. $165-170{ }^{\circ} \mathrm{C}$. Anal. Calcd for $\mathrm{C}_{17} \mathrm{H}_{24} \mathrm{~N}_{4} \mathrm{O} \bullet 2 \mathrm{HBr} \bullet 0.5 \mathrm{H}_{2} \mathrm{O}: \mathrm{C}, 43.33 ; \mathrm{H}, 5.77 ; \mathrm{N}, 11.89$. Found: C, 43.05; H, 5.64; N, 11.88 .

4-(3-Furyl)-2-(4-methylpiperazin-1-yl)-6-(trifluoromethyl)pyrimidine (16). Yield 81\% (free base); an oil. A hydrochloride salt: m.p. $>300{ }^{\circ} \mathrm{C} ;{ }^{1} \mathrm{H}-\mathrm{NMR}: \delta 8.77(\mathrm{~s}, 1 \mathrm{H}), 7.88(\mathrm{~m}, 1 \mathrm{H}), 7.56(\mathrm{~m}, 1 \mathrm{H}), 3.98(\mathrm{~m}, 4 \mathrm{H})$, $2.55(\mathrm{~m}, 4 \mathrm{H}), 2.39(\mathrm{~s}, 3 \mathrm{H})$. Anal. Calcd for $\mathrm{C}_{14} \mathrm{H}_{15} \mathrm{~N}_{4} \mathrm{~F}_{3} \mathrm{O} \bullet \mathrm{HCl} \bullet 0.25 \mathrm{H}_{2} \mathrm{O}: \mathrm{C}, 47.00 ; \mathrm{H}, 4.71 ; \mathrm{N}, 15.86$. Found: $\mathrm{C}, 47.40 ; \mathrm{H}, 4.61 ; \mathrm{N}, 15.72$.

4-(Cyclohexenylethynyl)-6-(3-furyl)-2-(4-methylpiperazin-1-yl)pyrimidine (17). Yield 8\%; a colorless oil (free base); ${ }^{1} \mathrm{H}-\mathrm{NMR}: 1.68\left(\mathrm{~m}, 4 \mathrm{H}, \mathrm{CH}_{2}\right), 2.18(\mathrm{~m}, 2 \mathrm{H}), 2.27(\mathrm{~m}, 2 \mathrm{H}), 2.34\left(\mathrm{~s}, 3 \mathrm{H}, \mathrm{CH}_{3}\right), 2.48(\mathrm{t}, J=5 \mathrm{~Hz}, 4 \mathrm{H})$, $3.90(\mathrm{t}, J=5 \mathrm{~Hz}, 4 \mathrm{H}), 6.39(\mathrm{~m}, 1 \mathrm{H}), 6.74(\mathrm{~s}, 1 \mathrm{H}), 6.86(\mathrm{~m}, 1 \mathrm{H}), 7.49(\mathrm{~m}, 1 \mathrm{H}), 8.07(\mathrm{~m}, 1 \mathrm{H}) ;{ }^{13} \mathrm{C}-\mathrm{NMR}$ : 反 21.3, 22.2, 25.9, 28.7, 43.6, 46.2, 55.0, 85.7, 93.2, 108.3, 108.5, 119.9, 125.9, 138.5, 143.1, 143.9, 151,8, 159.1, 161.8. A dihydrobromide salt: m.p. $188-190{ }^{\circ} \mathrm{C}$. Anal. Calcd for $\mathrm{C}_{21} \mathrm{H}_{24} \mathrm{~N}_{4} \mathrm{O} \bullet 2 \mathrm{HBr} \bullet 1.75 \mathrm{H}_{2} \mathrm{O}: \mathrm{C}, 46.55$; H, 5.49; N, 10.34. Found: C, 46.63; H, 5.09; N, 10.00 .

4,6-Bis(3-furyl)-2-(4-methylpiperazin-1-yl)pyrimidine (18) [24].

\subsection{Synthesis of 4-Dimethylamino-6-(3-furyl)-2-(4-methylpiperazin-1-yl)pyrimidine (19)}

This compound was obtained by: (1) addition reaction of 3-furyllithium with 2,4-dichloropyrimidine; (2) aromatization of the intermediate dihydropyrimidine with DDQ by using the general procedure described above; (3) treatment of the crude product [2,4-dichloro-6- 
(3-furyl)pyrimidine] with dimethylamine in ethanol at $23^{\circ} \mathrm{C}$, which caused a selective displacement of the 4-chloro atom to yield 2-chloro-4-dimethylamino-6-(3-furyl)pyrimidine; and (4) the treatment of this product with 4-methylpiperazine at elevated temperature using the general procedure described above.

Yield 30\%; a colorless oil (free base); ${ }^{1} \mathrm{H}-\mathrm{NMR}: \delta 8.17(\mathrm{~m}, 1 \mathrm{H}), 7.90(\mathrm{~m}, 1 \mathrm{H}), 7.48(\mathrm{~m}, 1 \mathrm{H}), 6.95(\mathrm{~s}, 1 \mathrm{H})$, $3.86(\mathrm{~m}, 4 \mathrm{H}), 2.48(\mathrm{~m}, 4 \mathrm{H}), 2.35(\mathrm{~s}, 3 \mathrm{H}), 2.20(\mathrm{~s}, 6 \mathrm{H}) ;{ }^{1} \mathrm{H}-\mathrm{NMR}$ NOE experiment: Irradiation at $\delta 2.20$ $\left(\mathrm{NMe}_{2}\right)$ gave a strong NOE signal at $\delta 6.95$ for $\mathrm{C} 5-\mathrm{H}$ of the pyrimidine, which is fully consistent with the given structure. HR-MS (ESI). Calcd for $\mathrm{C}_{15} \mathrm{H}_{21} \mathrm{~N}_{5} \mathrm{O}: \mathrm{m} / z$ 287.1745. Found: $m / z 2871748$.

4-(3-Furyl)-2,4-bis(4-methylpiperazin-1-yl)pyrimidine (20)

This compound was obtained by treatment of 2,4-dichloro-6-(furan-3-yl)pyrimidine described above with 4-methylpiperazine at $75^{\circ} \mathrm{C}$ by using the general procedure described above.

Yield 37\% (free base); an oil; ${ }^{1} \mathrm{H}-\mathrm{NMR}: \delta 7.47(\mathrm{~m}, 1 \mathrm{H}), 7.05(\mathrm{~m}, 1 \mathrm{H}), 6.53(\mathrm{~m}, 1 \mathrm{H}), 6.31(\mathrm{~s}, 1 \mathrm{H}), 3.85(\mathrm{t}$, $J=4.8 \mathrm{~Hz}, 4 \mathrm{H}), 3.67(\mathrm{t}, J=4.8 \mathrm{~Hz}, 4 \mathrm{H}), 2.47(\mathrm{t}, J=4.8 \mathrm{~Hz}, 8 \mathrm{H}), 2.34(\mathrm{~s}, 6 \mathrm{H}) ;{ }^{13} \mathrm{C}-\mathrm{NMR}: \delta 163.4,161.7$, 155.4, 153.8, 143.2, 111.8, 109.7, 86.9, 55.2, 54.8, 46.3, 46.2, 43.9, 43.8. Anal. Calcd for $\mathrm{C}_{18} \mathrm{H}_{26} \mathrm{~N}_{6} \mathrm{O} \cdot 3 \mathrm{HBr}$ : C, 36.94; H, 5.00; N, 14.36. Found: C, 37.14; H, 5.29; N, 14.62 .

4-(3-Furyl)-2-(4-methylpiperazino)-5-propylpyrimidine (21). Yield 44\%; an oil; ${ }^{1} \mathrm{H}-\mathrm{NMR}$ (free base): $\delta 8.17$ $(\mathrm{m}, 1 \mathrm{H}), 7.91(\mathrm{~m}, 1 \mathrm{H}), 7.48(\mathrm{~m}, 1 \mathrm{H}), 6.95(\mathrm{~s}, 1 \mathrm{H}), 3.85(\mathrm{~m}, 4 \mathrm{H}), 2.59(\mathrm{t}, J=7.6 \mathrm{~Hz}, 2 \mathrm{H}), 2.49(\mathrm{~m}, 4 \mathrm{H}), 2.35$ $(\mathrm{s}, 3 \mathrm{H}), 1.59$ (sxt, $J=7.6 \mathrm{~Hz}, 2 \mathrm{H}), 0.99(\mathrm{t}, J=7.6 \mathrm{~Hz}, 3 \mathrm{H})$. A hydrobromide salt: m.p. 206-208 ${ }^{\circ} \mathrm{C}$. Anal. Calcd for $\mathrm{C}_{16} \mathrm{H}_{22} \mathrm{~N}_{4} \mathrm{O} \bullet \mathrm{HBr}$ : C, 52.32; H, 6.31; N, 15.25. Found: C, 52.34; $\mathrm{H}, 6.11 ; \mathrm{N}, 15.12$.

4-n-Butyl-6-(3-furyl)-2-(4-methylpiperazino)-5-propylpyrimidine (22). Yield 73\% (free base); an oil; ${ }^{1} \mathrm{H}-\mathrm{NMR}: \delta 7.80(\mathrm{~m}, 1 \mathrm{H}), 7.47(\mathrm{~m}, 1 \mathrm{H}), 6.86(\mathrm{~m}, 1 \mathrm{H}), 3.84(\mathrm{~m}, 4 \mathrm{H}), 2.66(\mathrm{~m}, 2 \mathrm{H}), 2.59(\mathrm{~m}, 2 \mathrm{H}), 2.47$ $(\mathrm{m}, 4 \mathrm{H}), 2.34(\mathrm{~s}, 3 \mathrm{H}), 1.69(\mathrm{~m}, 2 \mathrm{H}), 1.47(\mathrm{~m}, 4 \mathrm{H}), 1.01(\mathrm{t}, J=7.6 \mathrm{~Hz}, 3 \mathrm{H}), 0.96(\mathrm{t}, J=7.6 \mathrm{~Hz}, 3 \mathrm{H})$. A dihydrobromide salt: m.p. $203{ }^{\circ} \mathrm{C}$ (dec.). Anal. Calcd for $\mathrm{C}_{20} \mathrm{H}_{30} \mathrm{~N}_{4} \mathrm{O} \bullet 2 \mathrm{HBr}$ : C, 47.63; H, 6.40; N, 11.11. Found: $\mathrm{C}, 47.34 ; \mathrm{H}, 6.65 ; \mathrm{N}, 11.08$.

4-(2-Methyl-3-furyl)-2-(4-methylpiperazin-1-yl)pyrimidine (23). Yield 39\% (free base); an oil. A dihydrobromide salt: m.p. $263-265{ }^{\circ} \mathrm{C} ;{ }^{1} \mathrm{H}-\mathrm{NMR}: \delta 2.66\left(\mathrm{~s}, 3 \mathrm{H}, \mathrm{CH}_{3}\right), 2.85(\mathrm{~s}, 3 \mathrm{H}), 3.11(\mathrm{~m}, 2 \mathrm{H})$, $3.40\left(\mathrm{~m}, 2 \mathrm{H}, \mathrm{CH}_{2}\right), 3.55(\mathrm{~m}, 2 \mathrm{H}), 4.73(\mathrm{~m}, 2 \mathrm{H}), 6.96(\mathrm{~m}, 1 \mathrm{H}), 6.98(\mathrm{~m}, 1 \mathrm{H}), 7.59(\mathrm{~m}, 1 \mathrm{H}), 8.41(\mathrm{~m}, 1 \mathrm{H})$, $10.00\left(\mathrm{bs}, 1 \mathrm{H}\right.$, exchangeable with $\mathrm{D}_{2} \mathrm{O}$ ). Anal. Calcd for $\mathrm{C}_{14} \mathrm{H}_{18} \mathrm{~N}_{4} \mathrm{O} \bullet 2 \mathrm{HBr} \bullet 0.5 \mathrm{H}_{2} \mathrm{O}: \mathrm{C}, 39.18 ; \mathrm{H}, 4.93$; N, 13.06. Found: C, 39.18; H, 4.77; N, 13.32 .

4-(5-Methyl-3-furyl)-2-(4-methylpiperazin-1-yl)pyrimidine (24). Yield 58\% (free base); an oil. A dihydrobromide salt: m.p. $275{ }^{\circ} \mathrm{C}$ (dec.); ${ }^{1} \mathrm{H}-\mathrm{NMR}: \delta 2.30\left(\mathrm{~s}, 3 \mathrm{H}, \mathrm{CH}_{3}\right), 2.84\left(\mathrm{~m}, 3 \mathrm{H}, \mathrm{CH}_{3}\right), 3.10$ $(\mathrm{m}, 2 \mathrm{H}), 3.31(\mathrm{~m}, 2 \mathrm{H}), 3.53(\mathrm{~m}, 2 \mathrm{H}), 4.79(\mathrm{~m}, 2 \mathrm{H}), 6.72(\mathrm{~m}, 1 \mathrm{H}), 7.04(\mathrm{~m}, 1 \mathrm{H}), 8.41(\mathrm{~m}, 2 \mathrm{H}), 9.98(\mathrm{bs}, 1 \mathrm{H}$, exangeable with $\mathrm{D}_{2} \mathrm{O}$ ). Anal. Calcd for $\mathrm{C}_{14} \mathrm{H}_{18} \mathrm{~N}_{4} \mathrm{O} \bullet 2 \mathrm{HBr} \bullet 0.5 \mathrm{H}_{2} \mathrm{O}: \mathrm{C}, 39.18 ; \mathrm{H}, 4.93 ; \mathrm{N}, 13.06$. Found: C, 39.01; H, 4.70; N, 13.02 .

4-n-Hexyl-6-(5-methyl-3-furyl)-2-(4-methylpiperazin-1-yl)pyrimidine (25). Yield 22\% (free base); an oil. A dihydrobromide salt: m.p. $242{ }^{\circ} \mathrm{C}$ (dec.); ${ }^{1} \mathrm{H}-\mathrm{NMR}: \delta 0.88(\mathrm{~m}, 3 \mathrm{H}), 1.34(\mathrm{~m}, 6 \mathrm{H}), 1.69(\mathrm{~m}, 2 \mathrm{H})$, $2.31(\mathrm{~s}, 3 \mathrm{H}), 2.57(\mathrm{t}, J=4.5 \mathrm{~Hz}, 2 \mathrm{H}), 2.86(\mathrm{~m}, 3 \mathrm{H}), 3.10(\mathrm{~m}, 2 \mathrm{H}), 3.26(\mathrm{~m}, 2 \mathrm{H}), 3.50(\mathrm{~m}, 2 \mathrm{H}), 4.81(\mathrm{~m}$, $2 \mathrm{H}), 6.67(\mathrm{~s}, 1 \mathrm{H}), 6.91(\mathrm{~s}, 1 \mathrm{H}), 8.28(\mathrm{~s}, 1 \mathrm{H}), 9.37\left(\mathrm{bs}, 1 \mathrm{H}\right.$, exchangeable with $\left.\mathrm{D}_{2} \mathrm{O}\right)$. Anal. Calcd for $\mathrm{C}_{20} \mathrm{H}_{30} \mathrm{~N}_{4} \mathrm{O} \bullet 2 \mathrm{HBr} \bullet \mathrm{H}_{2} \mathrm{O}: \mathrm{C}, 45.99 ; \mathrm{H}, 6.56 ; \mathrm{N}, 10.73$. Found: $\mathrm{C}, 45.81 ; \mathrm{H}, 6.44 ; \mathrm{N}, 10.54$.

4-(2-Furyl)-2-(4-methylpiperazin-1-yl)pyrimidine (26) [29].

4-Ethyl-6-(2-furyl)-2-(4-methylpiperazin-1-yl)pyrimidine (27). Yield 61\% (free base); an oil; ${ }^{1} \mathrm{H}-\mathrm{NMR}$ : $\delta 7.52$ $(\mathrm{m}, 1 \mathrm{H}), 7.12(\mathrm{~d}, J=3.2 \mathrm{~Hz}, 1 \mathrm{H}), 6.77(\mathrm{~s}, 1 \mathrm{H}), 6.51(\mathrm{~m}, 1 \mathrm{H}), 3.91(\mathrm{t}, J=4.8 \mathrm{~Hz}, 4 \mathrm{H}), 2.64(\mathrm{q}, J=7.4 \mathrm{~Hz}, 2 \mathrm{H})$, $2.48(\mathrm{t}, J=4.8 \mathrm{~Hz}, 4 \mathrm{H}), 2.34(\mathrm{~s}, 3 \mathrm{H}), 1.27(\mathrm{t}, J=7.4 \mathrm{~Hz}, 3 \mathrm{H}) ;{ }^{13} \mathrm{C}-\mathrm{NMR}: \delta 173.2,162.0,155.8,153.3,144.1$, 112.1, 110.8, 102.4, 55.3, 46.5, 43.8, 31.4, 12.7. HR-MS (ESI). Calcd for $\mathrm{C}_{15} \mathrm{H}_{21} \mathrm{~N}_{4} \mathrm{O}\left(\mathrm{M}^{+}+1\right): m / z 273.1725$. 
Found: $m / z$ 273.1715. A hydrobromide salt: m.p. $>250{ }^{\circ} \mathrm{C}$. Anal. Calcd for $\mathrm{C}_{15} \mathrm{H}_{20} \mathrm{~N}_{4} \mathrm{O} \cdot 2 \mathrm{HBr}: \mathrm{C}, 41.50$; H, 5.11; N, 12.70. Found: C, 41.79; H, 4.87; N, 12.38 .

4-n-Butyl-6-(2-furyl)-2-(4-methylpiperazin-1-yl)pyrimidine (28). Yield 78\% (free base); an oil; ${ }^{1} \mathrm{H}-\mathrm{NMR}$ : $\delta 7.52(\mathrm{~m}, 1 \mathrm{H}), 7.11(\mathrm{~d}, J=3.2 \mathrm{~Hz}, 1 \mathrm{H}), 6.75(\mathrm{~s}, 1 \mathrm{H}), 6.51(\mathrm{~m}, 1 \mathrm{H}), 3.90(\mathrm{t}, J=4.6 \mathrm{~Hz}, 4 \mathrm{H}), 2.60(\mathrm{t}$, $J=7.4 \mathrm{~Hz}, 2 \mathrm{H}), 2.48(\mathrm{t}, J=4.6 \mathrm{~Hz}, 4 \mathrm{H}), 2.34(\mathrm{~s}, 3 \mathrm{H}), 1.70(\mathrm{~m}, 2 \mathrm{H}), 1.40(\mathrm{~m}, 2 \mathrm{H}), 0.94(\mathrm{t}, \mathrm{J}=7.4 \mathrm{~Hz}, 3 \mathrm{H})$; ${ }^{13}$ C-NMR: $\delta$ 172.4, 162.1, 155.8, 153.4, 144.1, 112.2, 110.8, 103.1, 55.3, 46.5, 43.9, 38.1, 30.8, 22.7, 14.2 . HR-MS (ESI). Calcd for $\mathrm{C}_{17} \mathrm{H}_{25} \mathrm{~N}_{4} \mathrm{O}\left(\mathrm{M}^{+}+1\right): m / z$ 301.2026. Found: $m / z$ 301.2028. Anal. Calcd for $\mathrm{C}_{17} \mathrm{H}_{24} \mathrm{~N}_{4} \mathrm{O} \bullet \mathrm{HBr}: \mathrm{C}, 53.55 ; \mathrm{H}, 6.61 ; \mathrm{N}, 14.10$. Found: $\mathrm{C}, 53.34 ; \mathrm{H}, 6.60 ; \mathrm{N}, 14.49$.

4-(5-Methyl-2-furyl)-2-(4-methylpiperazin-1-yl)pyrimidine (29). Yield 48\% (free base); an oil. A dihydrobromide salt: m.p. $263-265{ }^{\circ} \mathrm{C} ;{ }^{1} \mathrm{H}-\mathrm{NMR}: \delta 2.39(\mathrm{~s}, 3 \mathrm{H}), 2.85(\mathrm{~m}, 3 \mathrm{H}), 3.11(\mathrm{~m}, 2 \mathrm{H}), 3.28$ (m), $3.54(\mathrm{~m}, 2 \mathrm{H}), 4.79(\mathrm{~m}, 2 \mathrm{H}), 6.36(\mathrm{~m}, 1 \mathrm{H}), 6.99(\mathrm{~m}, 1 \mathrm{H}), 7.28(\mathrm{~m}, 1 \mathrm{H}), 8.45(\mathrm{~m}, 1 \mathrm{H}), 9.78(\mathrm{bs}, 1 \mathrm{H}$, exchangeable with $\mathrm{D}_{2} \mathrm{O}$ ). Anal. Calcd for $\mathrm{C}_{14} \mathrm{H}_{18} \mathrm{~N}_{4} \mathrm{O} \bullet 2 \mathrm{HBr}$ : C, 40.02; $\mathrm{H}, 4.80 ; \mathrm{N}, 13.34$. Found: $\mathrm{C}$, 39.70; $\mathrm{H}, 4.85 ; \mathrm{N}, 13.25$.

2-(Methylpiperazin-1-yl)-4-(3-thienyl)pyrimidine (30) [25].

4-n-Butyl-2-(methylpiperazin-1-yl)-6-(3-thienyl)pyrimidine (31) [30].

2-(Methylpiperazin-1-yl)-4-(2-thienyl)pyrimidine (32) [24,26].

4-(2-Hydroxyphenyl)-2-(4-methylpiperazin-1-yl)pyrimidine (33) [27].

4-(3-Hydroxyphenyl)-2-(4-methylpiperazin-1-yl)pyrimidine (34) [27].

4-(4-Hydroxyphenyl)-2-(4-methylpiperazin-1-yl)pyrimidine (35) [27].

4-(Benzofuran-2-yl)-2-(4-methylpiperazin-1-yl)pyrimidine (36). Yield 71\% (free base); an oil; ${ }^{1} \mathrm{H}-\mathrm{NMR}$ : $\delta 8.45(\mathrm{~m}, 1 \mathrm{H}), 7.69(\mathrm{~m}, 1 \mathrm{H}), 7.58(\mathrm{~m}, 1 \mathrm{H}), 7.42(\mathrm{~m}, 1 \mathrm{H}), 7.30(\mathrm{~m}, 2 \mathrm{H}), 7.09(\mathrm{~m}, 1 \mathrm{H}), 3.98(\mathrm{~m}, 4 \mathrm{H}), 2.55$ $\left(\mathrm{m}, 4 \mathrm{H}, 2.39\right.$ (s, 3H). A hydrobromide salt: m.p. $>300{ }^{\circ} \mathrm{C}$. Anal. Calcd for $\mathrm{C}_{17} \mathrm{H}_{18} \mathrm{~N}_{4} \mathrm{O} \cdot 2 \mathrm{HBr}$ : C, 44.76; $\mathrm{H}, 4.42 ; \mathrm{N}, 12.28$. Found: $\mathrm{C}, 44.60 ; \mathrm{H}, 4.48 ; \mathrm{N}, 12.15$.

4-(Benzothiophen-2-yl)-2-(4-methylpiperazin-1-yl)pyrimidine (37). Yield 78\% (free base); an oil; ${ }^{1} \mathrm{H}-\mathrm{NMR}$ : $\delta 8.39(\mathrm{~d}, J=5.1 \mathrm{~Hz}, 1 \mathrm{H}), 7.96(\mathrm{~s}, 1 \mathrm{H}), 7.88(\mathrm{~m}, 2 \mathrm{H}), 7.41(\mathrm{~m}, 2 \mathrm{H}), 6.99(\mathrm{~d}, J=5.1 \mathrm{~Hz}, 1 \mathrm{H}), 3.98(\mathrm{~m}, 4 \mathrm{H})$, $2.55(\mathrm{~m}, 4 \mathrm{H}), 2.40(\mathrm{~s}, 3 \mathrm{H})$. A hydrobromide salt: m.p. $299-300{ }^{\circ} \mathrm{C}$. Anal. Calcd for $\mathrm{C}_{17} \mathrm{H}_{18} \mathrm{~N}_{4} \mathrm{~S} \bullet 2 \mathrm{HBr}$ : C, 43.24; H, 4.27; N, 11.86. Found: C, 43.20; H, 4.33; N, 11.80 .

4-(1-Methylindol-2-yl)-2-(4-methylpiperazin-1-yl)pyrimidine (38) [27].

2-(4-Methylpiperazin-1-yl)-4-(pyridin-3-yl)pyrimidine (39) [27].

2-(4-Methylpiperazin-1-yl)-4-(thiazol-2-yl)pyrimidine (40). Yield 77\% (free base); an oil; ${ }^{1} \mathrm{H}-\mathrm{NMR}: \delta 8.44$ (d, $J=5.0 \mathrm{~Hz}, 1 \mathrm{H}), 7.95(\mathrm{~d}, J=3.2 \mathrm{~Hz}, 1 \mathrm{H}), 7.48(\mathrm{~d}, J=3.2 \mathrm{~Hz}, 1 \mathrm{H}), 7.29(\mathrm{~d}, J=5.0 \mathrm{~Hz}, 1 \mathrm{H}), 3.92(\mathrm{t}, J=5.0 \mathrm{~Hz}$, 4H), $2.50(\mathrm{t}, J=5.0 \mathrm{~Hz}, 4 \mathrm{H}), 2.36(\mathrm{~s}, 3 \mathrm{H}) ;{ }^{13} \mathrm{C}-\mathrm{NMR}: \delta 168.4,161.4,159.0,157.7,144.3,122.1,104.3,54.8$, 46.1, 43.5. A hydrobromide salt: m.p. $273{ }^{\circ} \mathrm{C}$ (decomp.). Anal. Calcd for $\mathrm{C}_{12} \mathrm{H}_{15} \mathrm{~N}_{5} \mathrm{~S} \bullet \mathrm{HBr} \bullet 0.5 \mathrm{H}_{2} \mathrm{O}: \mathrm{C}$, 41.03; H, 4.88; N, 19.94. Found: C, 41.32; H, 4.64; N, 19.93.

(1H-Imidazol-1-yl)-2-(4-methylpiperazin-1-yl)pyrimidine (41). Yield 87\% (free base); an oil; ${ }^{1} \mathrm{H}-\mathrm{NMR}$ : $\delta 8.36$ $(\mathrm{s}, 1 \mathrm{H}), 8.36(\mathrm{~d}, J=5.4 \mathrm{~Hz}, 1 \mathrm{H}), 7.60(\mathrm{~s}, 1 \mathrm{H}), 7.17(\mathrm{~s}, 1 \mathrm{H}), 6.50(\mathrm{~d}, J=5.4 \mathrm{~Hz}, 1 \mathrm{H}), 3.90(\mathrm{t}, J=5.1 \mathrm{~Hz}, 4 \mathrm{H})$, $2.49(\mathrm{t}, J=5.1 \mathrm{~Hz}, 4 \mathrm{H}), 2.35(\mathrm{~s}, 3 \mathrm{H}) ;{ }^{13} \mathrm{C}-\mathrm{NMR}: \delta 161.4,160.1,155.3,135.0,130.8,115.6,96.5,54.8,46.1$, 43.7. A hydrobromide salt: m.p. $229-231^{\circ} \mathrm{C}$. Anal. Calcd for $\mathrm{C}_{12} \mathrm{H}_{16} \bullet 2 \mathrm{HBr} \bullet \mathrm{H}_{2} \mathrm{O}: \mathrm{C}, 33.98 ; \mathrm{H}, 4.75$; $\mathrm{N}, 19.81$. Found: C, 33.93; H, 4.55; N, 19.60 .

4-(3-Furyl)-2-(4-methylhomopiperazin-1-yl)pyrimidine (42). Yield 69\% (free base); an oil; ${ }^{1} \mathrm{H}-\mathrm{NMR}$ : $\delta 8,32$ $(\mathrm{d}, J=5.1 \mathrm{~Hz}, 1 \mathrm{H}), 8.08(\mathrm{~s}, 1 \mathrm{H}), 7.50(\mathrm{~m}, 1 \mathrm{H}), 6.88(\mathrm{~m}, 1 \mathrm{H}), 6.64(\mathrm{~d}, J=5.1 \mathrm{~Hz}, 1 \mathrm{H}), 4.01(\mathrm{~m}, 2 \mathrm{H}), 3.89(\mathrm{~m}$, $2 \mathrm{H}), 2.74(\mathrm{~m}, 2 \mathrm{H}), 2.60(\mathrm{~m}, 2 \mathrm{H}), 2.41(\mathrm{~s}, 3 \mathrm{H}), 2.04(\mathrm{~m}, 2 \mathrm{H})$. A hydrobromide salt: m.p. $176-177^{\circ} \mathrm{C}$. Anal. Calcd for $\mathrm{C}_{14} \mathrm{H}_{18} \mathrm{~N}_{4} \mathrm{O} \bullet 2 \mathrm{HBr} \bullet 1.25 \mathrm{H}_{2} 0: \mathrm{C}, 37.99 ; \mathrm{H}, 5.12 ; \mathrm{N}, 12.66$. Found: $\mathrm{C}, 37.96 ; \mathrm{H}, 5.12 ; \mathrm{N}, 12.51$. 
4-(3-Furyl)-2-(piperidin-1-yl)pyrimidine (43). Yield 68\% (free base); an oil; ${ }^{1} \mathrm{H}-\mathrm{NMR}$ : $\delta 8.32$ (d, $J=5.1 \mathrm{~Hz}$, $1 \mathrm{H}), 8.10(\mathrm{~m}, 1 \mathrm{H}), 7.51(\mathrm{~m}, 1 \mathrm{H}), 6.90(\mathrm{~m}, 1 \mathrm{H}), 6.62(\mathrm{~d}, J=5.1 \mathrm{~Hz}, 1 \mathrm{H}), 3.89(\mathrm{~m}, 4 \mathrm{H}), 1.67(\mathrm{~m}, 6 \mathrm{H})$. A hydrobromide salt: m.p. $190-191^{\circ} \mathrm{C}$. Anal. Calcd for $\mathrm{C}_{13} \mathrm{H}_{15} \mathrm{~N}_{3} \mathrm{O} \bullet \mathrm{HBr} \bullet 0.25 \mathrm{H}_{2} \mathrm{O}: \mathrm{C}, 49.66 ; \mathrm{H}, 5.28$; N, 13.35. Found: C, 49.60; H, 5.11, N, 13.37 .

4-(4-(3-Furyl)-2-(morpholin-1-yl)pyrimidine (44). Yield 53\% (free base); a white solid: m.p. $58-59{ }^{\circ} \mathrm{C}$; ${ }^{1}$ HNMR: $\delta 3.79(\mathrm{~m}, 4 \mathrm{H}), 3.87(\mathrm{~m}, 4 \mathrm{H}), 6.68(\mathrm{~d}, J=4.8 \mathrm{~Hz}, 1 \mathrm{H}), 6.88(\mathrm{~m}, 1 \mathrm{H}), 7.49(\mathrm{~m}, 1 \mathrm{H}), 8.08(\mathrm{~m}, 1 \mathrm{H})$, $8.31(\mathrm{~d}, J=4.8 \mathrm{~Hz}, 1 \mathrm{H})$. A hydrobromide salt: m.p. $215-216^{\circ} \mathrm{C}$; Anal. Calcd for $\mathrm{C}_{12} \mathrm{H}_{13} \mathrm{~N}_{3} \mathrm{O}_{2} \bullet \mathrm{HBr} \bullet 0.25$ $\mathrm{H}_{2} \mathrm{O}: \mathrm{C}, 45.51 ; \mathrm{H}, 4.62 ; \mathrm{N}, 13.27$. Found: $\mathrm{C}, 45.38 ; \mathrm{H}, 4.52 ; \mathrm{N}, 13.37$.

4-(3-Furyl)-N-[2-(morpholin-4-yl)ethyl]pyrimidin-2-amine (45). Yield 69\% (free base); an oil; ${ }^{1} \mathrm{H}-\mathrm{NMR}$ : $\delta 8.25(\mathrm{~d}, J=5.2 \mathrm{~Hz}, 1 \mathrm{H}), 8.07(\mathrm{~s}, 1 \mathrm{H}), 7.48(\mathrm{~d}, J=1.8 \mathrm{~Hz}, 1 \mathrm{H}), 6.85(\mathrm{~m}, 1 \mathrm{H}), 6.66(\mathrm{~d}, J=5.2 \mathrm{~Hz}, 1 \mathrm{H})$, $5.78(\mathrm{~s}, 1 \mathrm{H}), 3.71(\mathrm{t}, J=4.4 \mathrm{~Hz}, 4 \mathrm{H}), 3.55(\mathrm{q}, J=6 \mathrm{~Hz}, 2 \mathrm{H}), 2.59(\mathrm{t}, J=6 \mathrm{~Hz}, 2 \mathrm{H}), 2.49(\mathrm{t}, J=4.4 \mathrm{~Hz}, 4 \mathrm{H})$. A hydrobromide salt: m.p. $143-146{ }^{\circ} \mathrm{C}$. Anal. Calcd for $\mathrm{C}_{14} \mathrm{H}_{18} \mathrm{~N}_{4} \mathrm{O}_{2} \bullet 2 \mathrm{HBr} \bullet 0.5 \mathrm{H}_{2} \mathrm{O}: \mathrm{C}, 37.77 ; \mathrm{H}, 4.75$; $\mathrm{N}, 12.59$. Found: $\mathrm{C}, 37.78 ; \mathrm{H}, 4.76 ; \mathrm{N}, 12.20$.

4-(3-Furyl)-N-[3-(1H-imidazol-2-yl)propyl]pyrimidin-2-amine (46). Yield 62\% (free base); an oil; ${ }^{1} \mathrm{H}-\mathrm{NMR}$ : $\delta 8.24(\mathrm{~d}, J=5.2 \mathrm{~Hz}, 1 \mathrm{H}), 8.06(\mathrm{~m}, 1 \mathrm{H}), 7.49(\mathrm{~m}, 2 \mathrm{H}), 7.06(\mathrm{~s}, 1 \mathrm{H}), 6.94(\mathrm{~s}, 1 \mathrm{H}), 6.84(\mathrm{~m}, 1 \mathrm{H}), 6.70(\mathrm{~d}$, $J=5.2 \mathrm{~Hz}, 1 \mathrm{H}), 4.04(\mathrm{t}, J=6.8 \mathrm{~Hz}, 2 \mathrm{H}), 3.46(\mathrm{t}, J=6.8 \mathrm{~Hz}, 2 \mathrm{H}), 2.09(\mathrm{~m}, 2 \mathrm{H})$. A hydrobromide salt: m.p. 234-236 ${ }^{\circ} \mathrm{C}$. Anal. Calcd for $\mathrm{C}_{14} \mathrm{H}_{15} \mathrm{~N}_{5} \mathrm{O} \bullet 2 \mathrm{HBr} \bullet 0.5 \mathrm{H}_{2} \mathrm{O}: \mathrm{C}, 38.30 ; \mathrm{H}, 4.12 ; \mathrm{N}, 15.91$. Found: $\mathrm{C}, 38.23$; $\mathrm{H}, 3.93 ; \mathrm{N}, 15.78$.

\subsection{Synthesis of 4-[4-(3-Furyl)pyrimidin-2-yl]piperazine-1-spiro-1-morpholinium iodide (47)}

A mixture of compound 1 (1 mmol), 1-iodo-2-(2-iodoethoxy)ethane $(1 \mathrm{mmol})$ and anhydrous potassium carbonate $(140 \mathrm{mg}, 1 \mathrm{mmol})$ in anhydrous acetonitrile $(10 \mathrm{~mL})$ was heated under reflux for $1 \mathrm{~h}$ and then quenched with water $(5 \mathrm{~mL})$. Product 47 was extracted with ethyl acetate and purified on a chromatotron eluting with dichloromethane/methanol (8:2).

Yield 66\%; m.p. $>200{ }^{\circ} \mathrm{C}$ (decomp.); ${ }^{1} \mathrm{H}-\mathrm{NMR}$ (DMSO- $\left.d_{6}\right): \delta 8.55(\mathrm{~m}, 1 \mathrm{H}), 8.46(\mathrm{~d}, J=5.2 \mathrm{~Hz}, 1 \mathrm{H}), 7.83$ $(\mathrm{m}, 1 \mathrm{H}), 7.10(\mathrm{~m}, 2 \mathrm{H}), 4.13(\mathrm{~m}, 4 \mathrm{H}), 3.98(\mathrm{~m}, 4 \mathrm{H}), 3.74(\mathrm{~m}, 4 \mathrm{H}), 3.67(\mathrm{~m}, 4 \mathrm{H})$. HR-MS (ESI). Calcd for $\mathrm{C}_{16} \mathrm{H}_{21} \mathrm{~N}_{4} \mathrm{O}_{2}\left(\mathrm{M}^{+}\right): m / z$ 301.1665. Found: $m / z$ 301.1650. Anal. Calcd for $\mathrm{C}_{16} \mathrm{H}_{21} \mathrm{~N}_{4} \mathrm{IO}_{2}$ : C, 44.87; $\mathrm{H}, 4.94$; N, 13.08. Found: C, 44.97; H, 5.09; N, 12.69 .

4-(3-Furyl)-2-(methylpiperazin-1-yl)quinazoline (48) [27].

\subsection{Synthesis of 2,4-bis(4-Methylpiperazin-1-yl)quinazoline (49)}

This compound was obtained by treatment of 2,4-dichloroquinazoline with 4-methylpiperazine by using the general necleophilic displacement procedure described above.

Yield 46\% (free base); an oil; ${ }^{1} \mathrm{H}-\mathrm{NMR}: \delta 7.67(\mathrm{~d}, J=8.4 \mathrm{~Hz}, 1 \mathrm{H}), 7.51(\mathrm{~m}, 2 \mathrm{H}), 7.05(\mathrm{~m}, 1 \mathrm{H}), 3.93(\mathrm{~m}$, $4 \mathrm{H}), 3.70(\mathrm{t}, J=4.6 \mathrm{~Hz}, 4 \mathrm{H}), 2.61(\mathrm{t}, J=4.6 \mathrm{~Hz}, 4 \mathrm{H}), 2.51(\mathrm{t}, J=4.6 \mathrm{~Hz}, 4 \mathrm{H}), 2.372 \mathrm{~s}, 6 \mathrm{H}) ;{ }^{13} \mathrm{C}-\mathrm{NMR}$ : $\delta 165.8,158.4,154.6,132.6,126.4,125.3,120.8,112.2,55.3,55.1,49.9,46.4,46.3,44.1$. HR-MS (ESI). Calcd for $\mathrm{C}_{18} \mathrm{H}_{27} \mathrm{~N}_{6}\left(\mathrm{M}^{+}+1\right): m / z$ 327.2282. Found: $m / z$ 327.2297. A hydrobromide salt: m.p. $108-112{ }^{\circ} \mathrm{C}$. Anal. Calcd for $\mathrm{C}_{18} \mathrm{H}_{26} \mathrm{~N}_{6} \bullet 2 \mathrm{HBr}$ : C, 44.28; H 5.78; N, 17.21. Found: C, 44.60; H, 5.73; N, 17.42.

\subsection{Synthesis of 4-[2-(Dimethylamino)ethyl]-2-[2-(4-methylpiperazin-1-yl)quinazoline (50)}

The starting material, 2-chloro-4-vinylquinazoline, was obtained by the reaction of 2-chloroquinazoline with vinyllithium followed by aromatization of the resultant 4 -vinyldihydroquinazoline adduct by treatment with potassium ferricyanide(III) according to the described procedure [36].

The conjugate addition reaction of dimethylamine with 2-chloro-4-vinylquinazoline to give 2-chloro-4-(2-dimethylaminoethyl)quinazoline was conducted as described for the preparation of 
analogous compounds [27]. Treatment of this compound with 4-methylpiperazine to give the final product $\mathbf{5 0}$ was conducted by using a general procedure described above.

Yield 27\% (free base), an oil; ${ }^{1} \mathrm{H}-\mathrm{NMR}: \delta 7.86(\mathrm{~d}, J=8.0 \mathrm{~Hz}, 1 \mathrm{H}), 7.59(\mathrm{~m}, 2 \mathrm{H}), 7.18(\mathrm{t}, J=7.2 \mathrm{~Hz}, 1 \mathrm{H})$, $3.99(\mathrm{t}, J=5.0 \mathrm{~Hz}, 4 \mathrm{H}), 3.29(\mathrm{t}, J=7.2 \mathrm{~Hz}, 2 \mathrm{H}), 2.85(\mathrm{t}, J=7.2 \mathrm{~Hz}, 2 \mathrm{H}), 2.51(\mathrm{t}, J=5.0 \mathrm{~Hz}, 4 \mathrm{H}), 2.36(\mathrm{~s}, 6 \mathrm{H})$, 2.35 (s, 3H); ${ }^{13} \mathrm{C}-\mathrm{NMR}: \delta 170.1,158.4,152.3,133.3,126.4,124.6,122.1,118.6,57.6,55.1,46.3,45.5,43.8$, 32.4. HR-MS (ESI). Calcd for $\mathrm{C}_{17} \mathrm{H}_{26} \mathrm{~N}_{5}\left(\mathrm{M}^{+}+1\right): m / z 300.2175$. Found: $m / z 300.2188$. A hydrobromide salt: m.p. $100-106^{\circ} \mathrm{C}$. Anal. Calcd for $\mathrm{C}_{17} \mathrm{H}_{25} \mathrm{~N}_{5} \bullet 3.5 \mathrm{HBr} \bullet \mathrm{H}_{2} \mathrm{O}: \mathrm{C}, 34.00 ; \mathrm{H}, 5.12 ; \mathrm{N}, 11.66$. Found: $\mathrm{C}$, 33.74; H, 5.40; N, 11.26 .

\subsection{Synthesis of 2-(4-Methylpiperazin-1-yl)pyridines $\mathbf{5 1 - 5 3}$}

A mixture of furan-3-boronic acid, furan-2-boronic acid or thiophene-2-boronic acid (3.4 mmol), 4-bromo-2-chloropyrimidine $(0.25 \mathrm{~mL}, 2.3 \mathrm{mmol})$, potassium carbonate $(1.0 \mathrm{~g}, 7 \mathrm{mmol})$ and tetrakis(triphenylphosphine)palladium $[\mathrm{Pd}(\mathrm{PPh} 3) 4,0.2 \mathrm{~g}, 0.2 \mathrm{mmol}]$ in anhydrous dioxane $(6 \mathrm{~mL})$ was stirred under a nitrogen atmosphere and heated under reflux for 4 days. After cooling the mixture was filtered through a $0.5-\mathrm{cm}$ pad of Celite and concentrated under reduced pressure. A mixture of the crude product (2-chloro-4-heteroarylpyridine, $0.5 \mathrm{mmol}$ ) and 1-methylpiperazine $(1 \mathrm{~mL})$ in a sealed tube was heated at $200^{\circ} \mathrm{C}$ for $12 \mathrm{~h}$. The resultant brown oil was subjected to chromatography eluting with dichloromethane/methanol (95:5) to yield analytically pure product 51-53.

4-(3-Furyl)-2-(4-methylpiperazin-1-yl)pyridine (51). Yield 20\% (free base); an oil; ${ }^{1} \mathrm{H}-\mathrm{NMR}: \delta 8.16(\mathrm{~m}, 1 \mathrm{H})$, $7.81(\mathrm{~s}, 1 \mathrm{H}), 7.49(\mathrm{~m}, 1 \mathrm{H}), 6.72(\mathrm{~m}, 3 \mathrm{H}), 3.60(\mathrm{t}, J=5.0 \mathrm{~Hz}, 4 \mathrm{H}), 2.53(\mathrm{t}, J=5.0 \mathrm{~Hz}, 4 \mathrm{H}), 2.34(\mathrm{~s}, 3 \mathrm{H})$; ${ }^{13}$ C-NMR: $\delta 160,1,148.4,144.0,141.4,140.0,125.2,110.9,108.5,103.5,54.9,46.1,45.2$. A hydrobromide salt: m.p. $>250{ }^{\circ} \mathrm{C}$. Anal. Calcd for $\mathrm{C}_{14} \mathrm{H}_{17} \mathrm{~N}_{3} 0 \bullet 2 \mathrm{HBr}$ : C, 41.51; H, 4.73; N, 10.37. Found: C, 41.14; $\mathrm{H}, 4.39 ; \mathrm{N}, 11.07$.

4-(2-Furyl)-2-(4-methylpiperazin-1-yl)pyridine (52). Yield 55\% (free base); an oil; ${ }^{1} \mathrm{H}-\mathrm{NMR}: \delta 8.17(\mathrm{~m}, 1 \mathrm{H})$, $7.49(\mathrm{~m}, 1 \mathrm{H}), 6.39(\mathrm{~s}, 1 \mathrm{H}), 6.86(\mathrm{~m}, 1 \mathrm{H}), 6.78(\mathrm{~m}, 1 \mathrm{H}), 6.49(\mathrm{~m}, 1 \mathrm{H}), 3.62(\mathrm{t}, J=5.0 \mathrm{~Hz}, 4 \mathrm{H}), 2.54(\mathrm{t}$, $J=5.0 \mathrm{~Hz}, 4 \mathrm{H}), 2.35$ (s, 3H); ${ }^{13} \mathrm{C}-\mathrm{NMR}: \delta 160.1,152.3,148.3,143.1,138.8,111.9,108.4,107.9,100.9$, 54.9, 46.2, 45.2. HR-MS (ESI). Calcd for $\mathrm{C}_{14} \mathrm{H}_{18} \mathrm{~N}_{3} \mathrm{O}\left(\mathrm{M}^{+}+1\right)$ : $m / z$ 244.1450. Found: $m / z$ 244.1459. A hydrobromide salt: m.p. $>250{ }^{\circ} \mathrm{C}$. Anal. Calcd for $\mathrm{C}_{14} \mathrm{H}_{17} \mathrm{~N}_{3} \mathrm{O} \cdot 2 \mathrm{HBr}$ : C, 41.51; H, 4.73; N, 10.37 . Found: C, 41.24; H, 4.78; N, 10.51 .

2-(4-Methylpiperazin-1-yl)-4-(2-thienyl)pyridine (53). Yield 34\% (free base); an oil; ${ }^{1} \mathrm{H}-\mathrm{NMR}$ : $\delta 8.18(\mathrm{~d}$, $J=5.2 \mathrm{~Hz}, 1 \mathrm{H}), 7.44(\mathrm{~m}, 1 \mathrm{H}), 7.36(\mathrm{~d}, J=4.5 \mathrm{~Hz}, 1 \mathrm{H}), 7.11(\mathrm{~m}, 1 \mathrm{H}), 6.86(\mathrm{~m}, 1 \mathrm{H}), 6.83(\mathrm{~s}, 1 \mathrm{H}), 3.62$ $(\mathrm{t}, J=5.0 \mathrm{~Hz}, 4 \mathrm{H}), 2.55(\mathrm{t}, J=5.0 \mathrm{~Hz}, 4 \mathrm{H}), 2.36(\mathrm{~s}, 3 \mathrm{H}) .{ }^{13} \mathrm{C}-\mathrm{NMR}: \delta 160.1,148.5,142.8,142.5,128.1$, $126.3,124.8,110.7,103.2,54.9,46.2,45.3$. A hydrobromide salt: m.p. $>250{ }^{\circ} \mathrm{C}$. Anal. Calcd for $\mathrm{C}_{14} \mathrm{H}_{17} \mathrm{~N}_{3} \mathrm{~S} \bullet 2 \mathrm{HBr} \bullet 0.5 \mathrm{H}_{2} 0: \mathrm{C}, 39.09 ; \mathrm{H}, 4.69 ; \mathrm{N}, 9.77$. Found: $\mathrm{C}, 39.46 ; \mathrm{H}, 4.80 ; \mathrm{N}, 9.44$.

\subsection{Synthesis of Pyridines 54-59}

A mixture of 4-bromo-6-methyl-2-(methylpiperazin-1-yl)pyridine or 4-bromo-2-(methylpiperazin1-yl)pyridine (0.4 mmol), furan-3-boronic acid, furan-2-boronic acid or thiophene-2-boronic acid $(0.5 \mathrm{mmol})$, tetrakis(triphenylphosphine)palladium $(0.03 \mathrm{~g}, 0.03 \mathrm{mmol})$ and potassium carbonate $0.17 \mathrm{~g}, 1.1 \mathrm{mmol})$ in DMF $(4.0 \mathrm{~mL})$ containing water $(0.3 \mathrm{~mL})$ in a sealed tube under a nitrogen atmosphere was stirred at $90^{\circ} \mathrm{C}$ for $12 \mathrm{~h}$. After cooling, the mixture was filtered through Celite and dissolved in ethyl acetate $(20 \mathrm{~mL})$. The solution was washed with water $(3 \times 25 \mathrm{~mL})$, brine $(20 \mathrm{~mL})$ and concentrated under reduced pressure. The residue was subjected to chromatography eluting with hexanes/ether (4:1, $200 \mathrm{~mL} ; 1: 1,150 \mathrm{~mL})$ and finally with hexanes/ether/methanol (10:10:1, $200 \mathrm{~mL})$ to give product $\mathbf{5 4 - 5 9}$.

4-(3-Furyl)-2-methyl-6-(4-methylpiperazin-1-yl)pyridine (54). Yield 31\% (free base); an oil; ${ }^{1} \mathrm{H}-\mathrm{NMR}$ : $\delta 7.79$ $(\mathrm{s}, 1 \mathrm{H}), 7.48(\mathrm{~s}, 1 \mathrm{H}), 6.69(\mathrm{~s}, 1 \mathrm{H}), 6.62(\mathrm{~s}, 1 \mathrm{H}), 6.61(\mathrm{~s}, 1 \mathrm{H}), 3.60(\mathrm{t}, J=4.8 \mathrm{~Hz}, 4 \mathrm{H}), 2.55(\mathrm{t}, J=4.8 \mathrm{~Hz}$, $4 \mathrm{H}), 2.42(\mathrm{~s}, 3 \mathrm{H}), 2.36(\mathrm{~s}, 3 \mathrm{H}) ;{ }^{13} \mathrm{C}-\mathrm{NMR}: \delta 157.5,144.0,141.8,140.0,128.7,125.6,110.5,108.8,100.6$, 
55.1, 46.4, 45.5, 24.8. HR-MS (ESI). Calcd for $\mathrm{C}_{15} \mathrm{H}_{20} \mathrm{~N}_{2} \mathrm{O}\left(\mathrm{M}^{+}+1\right): \mathrm{m} / z$ 258.1606. Found: $m / z 258.1598$. A hydrobromide salt: m.p. $150-152{ }^{\circ} \mathrm{C}$. Anal. Calcd for $\mathrm{C}_{15} \mathrm{H}_{19} \mathrm{~N}_{3} \mathrm{O} \bullet \mathrm{HBr} \bullet 0.5 \mathrm{H}_{2} 0$ : C, 51.88; H, 6.10; $\mathrm{N}, 12.10$. Found: $\mathrm{C}, 51.90 ; \mathrm{H}, 6.50 ; \mathrm{N}, 12.06$.

4-(2-Furyl)-2-methyl-6-(4-methylpiperazin-1-yl)pyridine (55). Yield 10\% (free base); an oil; ${ }^{1} \mathrm{H}-\mathrm{NMR}: \delta 7.47$ $(\mathrm{s}, 1 \mathrm{H}), 6.75(\mathrm{~m}, 2 \mathrm{H}), 6.72(\mathrm{~s}, 1 \mathrm{H}), 6.47(\mathrm{~m}, 1 \mathrm{H}), 3.62(\mathrm{t}, J=4.8 \mathrm{~Hz}, 4 \mathrm{H}), 2.54(\mathrm{t}, J=4.8 \mathrm{~Hz}, 4 \mathrm{H}), 2.41(\mathrm{~s}$, 3H), 2.35 (s, 3H); ${ }^{13} \mathrm{C}-\mathrm{NMR}: 159.9,157.5,152.8,143.0,139.4,111.9,108.0,107.7,98.2,55.0,46.2,45.3,24.8$. HR-MS (ESI). Calcd for $\mathrm{C}_{15} \mathrm{H}_{20} \mathrm{~N}_{3} \mathrm{O}\left(\mathrm{M}^{+}+1\right): \mathrm{m} / z$ 258.1606. Found: $m / z 258.1618$. A hydrobromide salt: m.p. $148-150{ }^{\circ} \mathrm{C}$. Anal. Calcd for $\mathrm{C}_{15} \mathrm{H}_{19} \mathrm{~N}_{3} \mathrm{O} \bullet \mathrm{HBr} \bullet \mathrm{H}_{2} \mathrm{O}: \mathrm{C}, 50.57 ; \mathrm{H}, 6.22 ; \mathrm{N}, 11.79$. Found: C, 50.41; $\mathrm{H}, 6.42 ; \mathrm{N}, 11.39$.

2-Methyl-6-(4-methylpiperazin-1-yl)-4-(2-thienyl)pyridine (56). Yield 6\% (free base); an oil; ${ }^{1} \mathrm{H}-\mathrm{NMR}: \delta 7.41$ $(\mathrm{d}, J=3.2 \mathrm{~Hz}, 1 \mathrm{H}), 7.34(\mathrm{~d}, J=4.8 \mathrm{~Hz}, 1 \mathrm{H}), 7.09(\mathrm{~m}, 1 \mathrm{H}), 6.74(\mathrm{~s}, 1 \mathrm{H}), 6.63(\mathrm{~s}, 1 \mathrm{H}), 3.61(\mathrm{t}, J=4.8 \mathrm{~Hz}, 4 \mathrm{H})$, $2.55(\mathrm{t}, J=4.8 \mathrm{~Hz}, 4 \mathrm{H}), 2.43(\mathrm{~s}, 3 \mathrm{H}), 2.36(\mathrm{~s}, 3 \mathrm{H})$. A hydrobromide salt: m.p. 132-134 ${ }^{\circ} \mathrm{C}$. Anal. Calcd for $\mathrm{C}_{15} \mathrm{H}_{19} \mathrm{~N}_{3} \mathrm{~S} \bullet \mathrm{HBr}: \mathrm{C}, 50.85 ; \mathrm{H}, 5.68 ; \mathrm{N}, 11.86$. Found: C, 51.10; H, 5.69; N, 11.53.

6-(3-Furyl)-2-(4-methylpiperazin-1-yl)pyridine (57). Yield 80\% (free base); an oil; ${ }^{1} \mathrm{H}-\mathrm{NMR}$ : $\delta 7.99$ (s, $1 \mathrm{H}), 7.49(\mathrm{~m}, 1 \mathrm{H}), 7.30(\mathrm{~m}, 2 \mathrm{H}), 6.85(\mathrm{~m}, 1 \mathrm{H}), 6.54(\mathrm{~m}, 1 \mathrm{H}), 3.64(\mathrm{t}, J=5.0 \mathrm{~Hz}, 4 \mathrm{H}), 2.57(\mathrm{t}, J=5.0 \mathrm{~Hz}$, 4H), 2.37 (s, 3H); ${ }^{13} \mathrm{C}-\mathrm{NMR}: \delta$ 159.1, 149.8, 143.4, 141.1, 138.0, 127.7, 109.5, 108.8, 105.0, 54.9, 46.3, 45.5. HR-MS (ESI). Calcd for $\mathrm{C}_{14} \mathrm{H}_{18} \mathrm{~N}_{3} \mathrm{O}\left(\mathrm{M}^{+}+1\right): \mathrm{m} / z$ 244.1461. Found: $\mathrm{m} / z$ 244.1450. A hydrobromide salt: m.p. $>250{ }^{\circ} \mathrm{C}$. Anal. Calcd for $\mathrm{C}_{14} \mathrm{H}_{17} \mathrm{~N}_{3} \mathrm{O} \bullet 2 \mathrm{HBr} \bullet 2 \mathrm{H}_{2} \mathrm{O}: \mathrm{C}, 38.12 ; \mathrm{H}, 5.25 ; \mathrm{N}, 9.52$. Found: $\mathrm{C}, 38.23$; $\mathrm{H}, 5.33 ; \mathrm{N}, 9.72$.

2-(4-Methylpiperazin-1-yl)-6-(3-thienyl)pyridine (58). Yield 42\% (free base); an oil; ${ }^{1} \mathrm{H}-\mathrm{NMR}$ : $\delta 7.86$ (m, $1 \mathrm{H}), 7.63(\mathrm{~m}, 1 \mathrm{H}), 7.49(\mathrm{t}, J=4.0 \mathrm{~Hz}, 1 \mathrm{H}), 7.33(\mathrm{~m}, 1 \mathrm{H}), 6.97(\mathrm{~d}, J=4.0 \mathrm{~Hz}, 1 \mathrm{H}), 6.54(\mathrm{~d}, J=4.0 \mathrm{~Hz}$, $1 \mathrm{H}), 3.64(\mathrm{t}, J=5.0 \mathrm{~Hz}, 4 \mathrm{H}), 2.53(\mathrm{t}, J=5.0 \mathrm{~Hz}, 4 \mathrm{H}), 2.35(\mathrm{~s}, 3 \mathrm{H}) ;{ }^{13} \mathrm{C}-\mathrm{NMR}: \delta$ 159.0, 154.4, 143.0, 138.2, 126.4, 125.7, 123.0, 109.7, 105.2, 55.0, 46.3, 45.1. A hydrobromide salt: m. p. $>250{ }^{\circ} \mathrm{C}$. Anal. Calcd for $\mathrm{C}_{14} \mathrm{H}_{17} \mathrm{~N}_{3} \mathrm{~S} \bullet 2 \mathrm{HBr} \bullet \mathrm{H}_{2} \mathrm{O}: \mathrm{C}, 39.09 ; \mathrm{H}, 4.69 ; \mathrm{N}, 9.77$. Found: C, 39.11; H, 4.79; N, 9.90.

2-(2-Furyl)-6-(4-methylpiperazin-1-yl)pyridine (59). Yield 38\% (free base); an oil; ${ }^{1} \mathrm{H}-\mathrm{NMR}: \delta 8.17$ (d, $J=5.2 \mathrm{~Hz}, 1 \mathrm{H}), 7.48(\mathrm{~d}, J=1.6 \mathrm{~Hz}, 1 \mathrm{H}), 6.92(\mathrm{~m}, 1 \mathrm{H}), 6.85(\mathrm{~d}, J=5.2 \mathrm{~Hz}, 1 \mathrm{H}), 6.77(\mathrm{~d}, J=3.6 \mathrm{~Hz}, 1 \mathrm{H})$, $6.57(\mathrm{~d}, J=3.6 \mathrm{~Hz}, 1 \mathrm{H}), 3.61(\mathrm{t}, J=5.2 \mathrm{~Hz}, 4 \mathrm{H}), 2.52(\mathrm{t}, J=5.2 \mathrm{~Hz}, 4 \mathrm{H}), 2.34) \mathrm{s}, 3 \mathrm{H}) ;{ }^{13} \mathrm{C}-\mathrm{NMR}: \delta 160.1$, $152.3,148.3,143.1,138.8,111.9,108.4,107.9,100.9,54.9,46.2,45.2$. A hydrobromide salt: m.p. $>250{ }^{\circ} \mathrm{C}$. Anal. Calcd for $\mathrm{C}_{14} \mathrm{H}_{17} \mathrm{~N}_{3} \mathrm{O} \bullet 2 \mathrm{HBr} \bullet 2 \mathrm{H}_{2} \mathrm{O}: \mathrm{C}, 38.12 ; \mathrm{H}, 5.25 ; \mathrm{N}$, 9.52. Found: $\mathrm{C}, 37.94 ; \mathrm{H}, 5.02 ; \mathrm{N}, 9.54$.

\subsection{Synthesis of Substituted Benzenes 60-71}

A mixture of 1,3-dibromobenzene, 1,3-dibromo-5-methylbenzene or 1,3-dibromo-5-n-butylbenzene $(21 \mathrm{mmol})$ and $\mathrm{N}$-methylpiperazine $(0.8 \mathrm{~mL}), 7.0 \mathrm{mmol})$ in toluene $(20 \mathrm{~mL})$ was stirred under a nitrogen atmosphere and treated quickly with 2,2'-bis(diphenylphosphino)-1,1'-binaphthyl (BINAP, $0.13 \mathrm{~g}$, $0.21 \mathrm{mmol})$ and tris (dibenzylideneacetone)dipalladium( $(0)\left(\mathrm{Pd}_{2} \mathrm{dba}_{3}, 0.05 \mathrm{~g}, 0.06 \mathrm{mmol}\right)$. The flask was refilled with nitrogen, capped with a rubber septum, and 1,8-diazabicyclo[5.4.0]undec-7-ene (DBU, $2.6 \mathrm{~mL}, 17.5 \mathrm{mmol}$ ) was added via a syringe. The mixture was warmed to $60{ }^{\circ} \mathrm{C}$ before treatment with sodium tert-butoxide $(0.01 \mathrm{~g}, 0.05 \mathrm{mmol})$ in one portion. The mixture was heated at $110^{\circ} \mathrm{C}$ for $12 \mathrm{~h}$, then cooled and partitioned between ethyl acetate (EtOAc, $40 \mathrm{~mL}$ ) and water $(40 \mathrm{~mL})$. The aqueous layer was extracted with EtOAc $(40 \mathrm{~mL})$. The organic layers were combined and washed with hydrochloric acid $(1.6 \mathrm{M}, 2 \times 25 \mathrm{~mL})$. The aqueous acidic layer containing product was made basic with $\mathrm{NaOH}$ solution $(1 \mathrm{M}, 50 \mathrm{~mL})$ and the mixture was extracted with EtOAc $(2 \times 40 \mathrm{~mL})$. The extract was washed with brine $(25 \mathrm{~mL})$, dried over magnesium sulfate, filtered and concentrated under reduced pressure to provide an analytically pure product.

1-(3-Bromophenyl)-4-methylpiperazine; yield 30\%; an oil; ${ }^{13} \mathrm{C}-\mathrm{NMR}$ : $\delta 152.6,130.5,123.4,122.3,118.8$, 114.5, 55.1, 48.8.46.3. HR-MS (ESI). Calcd for $\mathrm{C}_{11} \mathrm{H}_{15} \mathrm{BrN}_{2}\left(\mathrm{M}^{+}+1\right): \mathrm{m} / z$ 255.0497. Found: $m / z 255.0493$. 
1-(3-Bromo-5-methylphenyl)-4-methylpiperazine; yield 54\%; an oil; ${ }^{13} \mathrm{C}-\mathrm{NMR}$ : $\delta$ 152.5, 140.6, 131.1, 123.2, 116.1, 115.4, 55.2, 48.9, 46.3, 21.7. HR-MS (ESI). Calcd for $\mathrm{C}_{12} \mathrm{H}_{17} \mathrm{BrN}_{2}\left(\mathrm{M}^{+}+1\right): \mathrm{m} / z 269.0653$. Found: 269.0653 .

1-(3-Bromo-5-n-butylphenyl)-4-methylpiperazine; yield 32\%; an oil; ${ }^{13}$ C-NMR: $\delta 152.3,145.5,122.9,122.4$, 116.0, 114.7, 55.0, 48.7, 46.1, 35.8, 33.4, 22.3, 13.9. HR-MS (ESI). Calcd for $\mathrm{C}_{15} \mathrm{H}_{24} \mathrm{BrN}_{2}\left(\mathrm{M}^{+}+1\right)$ : $m / z$ 311.1123. Found: $m / z 311.1133$.

A bromophenylpiperazine derivative $(1.2 \mathrm{mmol})$, obtained as described above, was allowed to react with furan-3-boronic acid, furan-2-boronic acid, thiophene-3-boronic acid or thiophene-2-boronic acid $(1.8 \mathrm{mmol})$ in DMF $(5 \mathrm{~mL})$ and water $(0.5 \mathrm{~mL})$ in the presence of tetrakis(triphenylphosphine)palladium $(0)(0.09 \mathrm{mmol})$ and potassium carbonate $(0.5 \mathrm{~g}, 3.6 \mathrm{mmol})$ at $90{ }^{\circ} \mathrm{C}$ under a nitrogen atmosphere in a sealed tube for $12 \mathrm{~h}$. After cooling, the mixture was filtered through Celite and the adsorbent was washed with EtOAc $(20 \mathrm{~mL})$. Concentration followed by chromatography eluting with hexanes/ether (4:1) gave the oily product $\mathbf{6 0 - 7 1}$ that was additionally purified by crystallization of a hydrobromide salt from ethanol.

1-[3-(3-Furyl)phenyl]-4-methylpiperazine (60). Yield 34\%; ${ }^{1} \mathrm{H}-\mathrm{NMR}: \delta 7.70(\mathrm{~s}, 1 \mathrm{H}), 7.46(\mathrm{~s}, 1 \mathrm{H}), 7.26(\mathrm{t}$, $J=5.6 \mathrm{~Hz}, 1 \mathrm{H}), 7.03(\mathrm{~s}, 1 \mathrm{H}), 6.99(\mathrm{~d}, J=7.6 \mathrm{~Hz}, 1 \mathrm{H}), 6.85(\mathrm{~m}, 1 \mathrm{H}), 6.68(\mathrm{~s}, 1 \mathrm{H}), 3.27(\mathrm{t}, J=4.8 \mathrm{~Hz}, 4 \mathrm{H})$, $2.62(\mathrm{t}, J=4.8 \mathrm{~Hz}, 4 \mathrm{H}), 2.38(\mathrm{~s}, 3 \mathrm{H}){ }^{13} \mathrm{C}-\mathrm{NMR}: \delta 151.9,143.6,138.7,133.5,129.7,127.1,117.8,115.0,113.9$, 109.2, 55.3, 49.3, 46.3. HR-MS (ESI). Calcd for $\mathrm{C}_{15} \mathrm{H}_{19} \mathrm{~N}_{2} \mathrm{O}\left(\mathrm{M}^{+}+1\right): m / z$ 243.1497. Found: $m / z 243.1492$. A hydrobromide salt: m.p. $215-217^{\circ} \mathrm{C}$. Anal. Calcd for $\mathrm{C}_{15} \mathrm{H}_{18} \mathrm{~N}_{2} \mathrm{O} \bullet 2 \mathrm{HBr}: \mathrm{C}, 44.58 ; \mathrm{H}, 4.99 ; \mathrm{N}, 6.93$. Found: C, 44.31; H, 4.99; N, 6.62.

1-[3-(3-Furyl)-5-methylphenyl]-4-methylpiperazine (61). Yield 25\%; ${ }^{1} \mathrm{H}-\mathrm{NMR}$ : $\delta 7.68(\mathrm{~s}, 1 \mathrm{H}), 7.44(\mathrm{~s}, 1 \mathrm{H})$, $6.85(\mathrm{~s}, 1 \mathrm{H}), 6.82(\mathrm{~s}, 1 \mathrm{H}), 6.67(\mathrm{~s}, 2 \mathrm{H}), 3.23(\mathrm{t}, J=4.8 \mathrm{~Hz}, 4 \mathrm{H}), 2.59(\mathrm{t}, J=4.8 \mathrm{~Hz}, 4 \mathrm{H}), 2.34(2 \mathrm{~s}, 6 \mathrm{H})$; ${ }^{13}$ C-NMR: $\delta 151.7,143.4,139.2,138.5,133.1,126.9,118.6,115.7,111.1,109.1,55.1,49.2,46.1,21.7$. HR-MS (ESI). Calcd for $\mathrm{C}_{16} \mathrm{H}_{21} \mathrm{~N}_{2} \mathrm{O}\left(\mathrm{M}^{+}+1\right): \mathrm{m} / z$ 257.1654. Found: $\mathrm{m} / \mathrm{z}$ 257.1657. A hydrobromide salt: m.p. $230-232{ }^{\circ} \mathrm{C}$. Anal. Calcd for $\mathrm{C}_{16} \mathrm{H}_{20} \mathrm{~N}_{2} \mathrm{O} \bullet 2 \mathrm{HBr}$ : C, 45.96; H, 5.30; N, 6.70. Found: C, 46.30; H, 5.28; $\mathrm{N}, 6.34$.

1-[3-n-Butyl-5-(3-furyl)phenyl]-4-methylpiperazine (62). Yield 70\%; ${ }^{1} \mathrm{H}-\mathrm{NMR}: \delta 7.69(\mathrm{~s}, 1 \mathrm{H}), 7.43(\mathrm{t}$, $J=1.6 \mathrm{~Hz}, 1 \mathrm{H}), 6.85(\mathrm{~s}, 1 \mathrm{H}), 6.82(\mathrm{~s}, 1 \mathrm{H}), 6.67(\mathrm{~m}, 2 \mathrm{H}), 3.23(\mathrm{t}, J=5.2 \mathrm{~Hz}, 4 \mathrm{H}), 2.57(\mathrm{~m}, 6 \mathrm{H}), 1.61(\mathrm{~m}$, 2H), $1.37(\mathrm{~m}, 2 \mathrm{H}), 0.93(\mathrm{t}, J=7.2 \mathrm{~Hz}, 3 \mathrm{H}) ;{ }^{13} \mathrm{C}-\mathrm{NMR}: \delta 151.8,144.4,143.4,138.5,133.1,127.1,118.1$, 115.4, 111.3, 109.2, 55.3, 49.4, 46.2, 36.2, 33.8, 22.6, 14.1. HR-MS (ESI). Calcd for $\mathrm{C}_{19} \mathrm{H}_{27} \mathrm{~N}_{2} \mathrm{O}\left(\mathrm{M}^{+}+1\right)$ : $\mathrm{m} / \mathrm{z}$ 299.2123. Found: $\mathrm{m} / \mathrm{z}$ 299.2136. A hydrobromide salt: m.p. $215-219{ }^{\circ} \mathrm{C}$. Anal. Calcd for $\mathrm{C}_{19} \mathrm{H}_{26} \mathrm{~N}_{2} \mathrm{O} \bullet 2 \mathrm{HBr} \bullet 0.5 \mathrm{H}_{2} \mathrm{O}: \mathrm{C}, 48.63 ; \mathrm{H}, 6.23 ; \mathrm{N}, 5.97$. Found: $\mathrm{C}, 48.55 ; \mathrm{H}, 6.14 ; \mathrm{N}, 6.20$.

1-[3-(2-Furyl)phenyl]-4-methylpiperazine (63). Yield 24\%; ${ }^{1} \mathrm{H}-\mathrm{NMR}: \delta 7.44(\mathrm{~s}, 1 \mathrm{H}), 7.27(\mathrm{~m}, 2 \mathrm{H}), 7.16$ $(\mathrm{d}, J=7.6 \mathrm{~Hz}, 1 \mathrm{H}), 6.84(\mathrm{~d}, J=7.6 \mathrm{~Hz}, 1 \mathrm{H}), 6.62(\mathrm{~m}, 1 \mathrm{H}), 6.45(\mathrm{~m}, 1 \mathrm{H}), 3.27(\mathrm{t}, J=4.6 \mathrm{~Hz}, 4 \mathrm{H}), 2.60$ $(\mathrm{t}, J=4.6 \mathrm{~Hz}, 4 \mathrm{H}), 2.36(\mathrm{~s}, 3 \mathrm{H}) ;{ }^{13} \mathrm{C}-\mathrm{NMR}: \delta 154.5,151.7,142.0,131.8,129.6,115.5,115.4,111.7,111.5$, 105.1, 55.3, 49.2, 46.3. HR-MS (ESI): Calcd for $\mathrm{C}_{15} \mathrm{H}_{19} \mathrm{~N}_{2} \mathrm{O}\left(\mathrm{M}^{+}+1\right): m / z$ 243.1497. Found: $m / z$ 243.1487. A hydrobromide salt: m.p. $240-242{ }^{\circ} \mathrm{C}$. Anal. Calcd for $\mathrm{C}_{15} \mathrm{H}_{18} \mathrm{~N}_{2} \mathrm{O} \bullet 2 \mathrm{HBr} \bullet 0.5 \mathrm{H}_{2} \mathrm{O}: \mathrm{C}, 43.61 ; \mathrm{H}, 5.12$; N, 6.78. Found: C, 43.24; H, 5.12; N, 7.15.

1-[3-(2-Furyl)-5-methylphenyl]-4-methylpiperazine (64). Yield 15\%; ${ }^{1} \mathrm{H}-\mathrm{NMR}: \delta 7.46(\mathrm{~s}, 1 \mathrm{H}), 7.09(\mathrm{~s}, 1 \mathrm{H})$, $7.03(\mathrm{~s}, 1 \mathrm{H}), 6.69(\mathrm{~m}, 1 \mathrm{H}), 6.63(\mathrm{~m}, 1 \mathrm{H}), 6.47(\mathrm{~m}, 1 \mathrm{H}), 3.31(\mathrm{t}, J=5.0 \mathrm{~Hz}, 4 \mathrm{H}), 2.67(\mathrm{t}, J=5.0 \mathrm{~Hz}, 4 \mathrm{H})$, $2.42(\mathrm{~s}, 3 \mathrm{H}), 2.36(\mathrm{~s}, 3 \mathrm{H}) ;{ }^{13} \mathrm{C}-\mathrm{NMR}: \delta 154.4,151.4,141.7,139.1,131.5,116.6,116.2,111.5,108.9,104.8$, 54.9, 48.9, 45.8, 21.8. HR-MS (ESI). Calcd for $\mathrm{C}_{16} \mathrm{H}_{21} \mathrm{~N}_{2} \mathrm{O}\left(\mathrm{M}^{+}+1\right): m / z$ 257.1654. Found: $m / z$ 257.1651. A hydrobromide salt: m.p. $245-249^{\circ} \mathrm{C}$. Anal. Calcd for $\mathrm{C}_{16} \mathrm{H}_{20} \mathrm{~N}_{2} \mathrm{O} \bullet 2 \mathrm{HBr}$ : C, 45.97; H, 5.30; N, 6.70 . Found: C, 45.64; H, 5.26; N, 6.81 .

1-[3-n-Butyl-5-(2-furyl)phenyl]-4-methylpiperazine (65). Yield 76\%; ${ }^{1} \mathrm{H}-\mathrm{NMR}: \delta 7.44(\mathrm{~s}, 1 \mathrm{H}), 7.07(\mathrm{~s}, 1 \mathrm{H})$, $7.01(\mathrm{~s}, 1 \mathrm{H}), 6.68(\mathrm{~m}, 1 \mathrm{H}), 6.61(\mathrm{~d}, J=3.2 \mathrm{~Hz}, 1 \mathrm{H}), 6.45 \mathrm{q}, J=3.2 \mathrm{~Hz}, 1 \mathrm{H}), 3.26(\mathrm{t}, J=4.8 \mathrm{~Hz}, 4 \mathrm{H})$, $2.59(\mathrm{t}, J=5.6 \mathrm{~Hz}, 6 \mathrm{H}), 2.36(\mathrm{~s}, 3 \mathrm{H}), 1.62(\mathrm{~m}, 2 \mathrm{H}), 1.37(\mathrm{~m}, 2 \mathrm{H}), 0.93(\mathrm{t}, J=7.2 \mathrm{~Hz}, 3 \mathrm{H}) ;{ }^{13} \mathrm{C}-\mathrm{NMR}:$ 
$\delta$ 154.7, 151.7, 144.4, 141.9, 131.7, 116.1, 116.0, 111.7, 109.2, 105.0, 55.3, 49.3, 46.2, 36.3, 33.8, 22.6, 14.2. HR-MS (ESI). Calcd for $\mathrm{C}_{19} \mathrm{H}_{27} \mathrm{~N}_{2} \mathrm{O}\left(\mathrm{M}^{+}+1\right): m / z$ 299.2123. Found: $m / z$ 299.2124. A hydrobromide salt: m.p. $180-182{ }^{\circ} \mathrm{C}$. Anal. Calcd for $\mathrm{C}_{19} \mathrm{H}_{26} \mathrm{~N}_{2} \mathrm{O} \bullet \mathrm{HBr}$ : C, 60.16; H, 7.17; N, 7.38. Found: C, 60.37; H, 7.15; $\mathrm{N}, 7.54$.

1-Methyl-4-[3-(3-thienyl)phenyl]piperazine (66). Yield 25\%; ${ }^{1} \mathrm{H}-\mathrm{NMR}: \delta 7.42(\mathrm{t}, J=2.0 \mathrm{~Hz}, 1 \mathrm{H}), 7.36(\mathrm{~d}$, $J=2.0 \mathrm{~Hz}, 2 \mathrm{H}), 7.29(\mathrm{t}, J=8 \mathrm{~Hz}, 1 \mathrm{H}), 7.14(\mathrm{~s}, 1 \mathrm{H}), 7.09(\mathrm{~d}, J=8.0 \mathrm{~Hz}, 1 \mathrm{H}), 6.87(\mathrm{~m}, 1 \mathrm{H}), 3.27(\mathrm{t}, J=4.8 \mathrm{~Hz}$, $4 \mathrm{H}), 2.62(\mathrm{t}, J=4.8 \mathrm{~Hz}, 4 \mathrm{H}), 2.38(\mathrm{~s}, 3 \mathrm{H}) ;{ }^{13} \mathrm{C}-\mathrm{NMR}: \delta 151.8,143.1,137.0,129.7,126.7,126.2,120.5$, $118.5,115.2,114.6,55.3,49.3,46.3$. HR-MS (ESI). Calcd for $\mathrm{C}_{15} \mathrm{H}_{19} \mathrm{~N}_{2} \mathrm{~S}\left(\mathrm{M}^{+}+1\right): \mathrm{m} / z$ 259.1269. Found: $m / z$ 259.1269. A hydrobromide salt: m.p. $200-205^{\circ} \mathrm{C}$. Anal. Calcd for $\mathrm{C}_{15} \mathrm{H}_{18} \mathrm{~N}_{2} \mathrm{~S} \bullet 3 \mathrm{HBr}$ : C, 35.95 ; H, 4.22; N, 5.66. Found: C, 35.97; H, 4.19; N, 5.66.

1-Methyl-4-[3-methyl-5-(3-thienyl)phenyl]piperazine (67). Yield 25\%; ${ }^{1} \mathrm{H}-\mathrm{NMR}: \delta 7.40(\mathrm{~s}, 1 \mathrm{H}), 7.35(\mathrm{~s}$, 2H), $6.95(\mathrm{~s}, 1 \mathrm{H}), 6.92(\mathrm{~s}, 1 \mathrm{H}), 6.70(\mathrm{~s}, 1 \mathrm{H}), 3.25(\mathrm{t}, J=4.8 \mathrm{~Hz}, 4 \mathrm{H}), 2.61(\mathrm{t}, J=4.8 \mathrm{~Hz}, 4 \mathrm{H}), 2.35(2 \mathrm{~s}$, $6 \mathrm{H}) ;{ }^{13} \mathrm{C}-\mathrm{NMR}: \delta 151.9,143.1,139.3,136.9,126.8,126.0,120.3,119.4,116.0,111.9,55.3,49.3,46.2,22.0$. HR-MS (ESI). Calcd for $\mathrm{C}_{16} \mathrm{H}_{21} \mathrm{~N}_{2} \mathrm{~S}\left(\mathrm{M}^{+}+1\right): m / z$ 273.1425. Found: $m / z$ 273.1432. A hydrobromide salt: m.p. $245-247^{\circ} \mathrm{C}$. Anal. Calcd for $\mathrm{C}_{16} \mathrm{H}_{20} \mathrm{~N}_{2} \mathrm{~S} \bullet 1.5 \mathrm{HBr} \bullet 2 \mathrm{H}_{2} \mathrm{O}: \mathrm{C}, 44.89 ; \mathrm{H}, 4.85 ; \mathrm{N}, 6.03$. Found: C, 44.71; $\mathrm{H}, 5.23 ; \mathrm{N}, 6.42$.

1-[3-n-Butyl-5-(3-thienyl)phenyl]-4-methylpiperazine (68). Yield 23\%; ${ }^{1} \mathrm{H}-\mathrm{NMR}: \delta 7.40(\mathrm{t}, J=2.4 \mathrm{~Hz}$, $1 \mathrm{H}), 7.35(\mathrm{~m}, 2 \mathrm{H}), 6.96(\mathrm{~s}, 1 \mathrm{H}), 6.92(\mathrm{~s}, 1 \mathrm{H}), 6.71(\mathrm{~s}, 1 \mathrm{H}), 3.26(\mathrm{t}, J=4.8 \mathrm{~Hz}, 4 \mathrm{H}), 2.60(\mathrm{~m}, 6 \mathrm{H}), 2.36$ $(\mathrm{s}, 3 \mathrm{H}), 1.62(\mathrm{~m}, 2 \mathrm{H}), 1.39(\mathrm{~m}, 2 \mathrm{H}), 0.93(\mathrm{t}, J=7.6 \mathrm{~Hz}, 3 \mathrm{H}) ;{ }^{13} \mathrm{C}-\mathrm{NMR}: \delta$ 151.9, 144.5, 143.3, 136.8, $126.9,126.0,120.3,118.9,115.6,112.1,55.4,49.5,46.3,36.3,33.9,22.7,14.2$. HR-MS (ESI). Calcd for $\mathrm{C}_{19} \mathrm{H}_{27} \mathrm{~N}_{2} \mathrm{~S}\left(\mathrm{M}^{+}+1\right): m / z$ 315.1895. Found: $m / z$ 315.1910. A hydrobromide salt: m.p. $215-217^{\circ} \mathrm{C}$. Anal. Calcd for $\mathrm{C}_{19} \mathrm{H}_{26} \mathrm{~N}_{2} \mathrm{~S} \bullet 2 \mathrm{HBr}$ : C, 47.91; H, 5.93; N, 5.93. Found: C, 47.60; H, 6.19; N, 6.20.

1-Methyl-4-[3-(2-thienyl)phenyl]piperazine (69). Yield 23\%; ${ }^{1} \mathrm{H}-\mathrm{NMR}: \delta 7.27(\mathrm{~m}, 3 \mathrm{H}), 7.15(\mathrm{~s}, 1 \mathrm{H}), 7.10(\mathrm{~d}$, $J=8.4 \mathrm{~Hz}, 1 \mathrm{H}), 7.06(\mathrm{~m}, 1 \mathrm{H}), 6.86(\mathrm{~m}, 1 \mathrm{H}), 3.26(\mathrm{t}, J=4.8 \mathrm{~Hz}, 4 \mathrm{H}), 2.59(\mathrm{t}, J=4.8 \mathrm{~Hz}, 4 \mathrm{H}), 2.36(\mathrm{~s}, 3 \mathrm{H})$; ${ }^{13}$ C-NMR: $\delta 151.7,144.9,135.2,129.6,127.8,124.6,123.0,117.7,115.2,113.8,55.1,49.0,46.1$. HR-MS (ESI). Calcd for $\mathrm{C}_{15} \mathrm{H}_{19} \mathrm{~N}_{2} \mathrm{~S}\left(\mathrm{M}^{+}+1\right): m / z$ 259.1269. Found: $m / z 259.1279$. A hydrobromide salt: $\mathrm{m} . p$. $>250{ }^{\circ}$ C. Anal. Calcd for $\mathrm{C}_{15} \mathrm{H}_{18} \mathrm{~N}_{2} \mathrm{~S} \bullet 2 \mathrm{HBr}$ : C, 42.87; H, 4.80; N, 6.67. Found: C, 42.55; H, 4.78; N, 6.65.

1-Methyl-4-[3-methyl-5-(2-thienyl)phenyl]piperazine (70). Yield 27\%; ${ }^{1} \mathrm{H}-\mathrm{NMR}$ : $\delta 7.26(\mathrm{~m}, 2 \mathrm{H}), 7.05(\mathrm{t}$, $J=3.6 \mathrm{~Hz}, 1 \mathrm{H}), 6.97(\mathrm{~m}, 2 \mathrm{H}), 6.69(\mathrm{~s}, 1 \mathrm{H}), 3.26(\mathrm{t}, J=4.8 \mathrm{~Hz}, 4 \mathrm{H}), 2.62(\mathrm{t}, J=4.8 \mathrm{~Hz}, 4 \mathrm{H}), 2.34(\mathrm{~s}, 3 \mathrm{H}), 2.36$ (s, 3H); ${ }^{13} \mathrm{C}-\mathrm{NMR}: \delta 151.7,145.0,139.3,135.1,127.8,124.4,123.0,118.7,116.2,111.1,55.1,49.1,46.1,21.7$. HR-MS (ESI). Calcd for $\mathrm{C}_{16} \mathrm{H}_{21} \mathrm{~N}_{2} \mathrm{~S}\left(\mathrm{M}^{+}+1\right): m / z$ 273.1425. Found: $m / z$ 273.1434. A hydrobromide salt: m.p. $>250{ }^{\circ} \mathrm{C}$. Anal. Calcd for $\mathrm{C}_{16} \mathrm{H}_{20} \mathrm{~N}_{2} \mathrm{~S} \bullet 2 \mathrm{HBr} \bullet 0.5 \mathrm{H}_{2} \mathrm{O}: \mathrm{C}, 43.36 ; \mathrm{H}, 5.23 ; \mathrm{N}, 6.23$. Found: C, 43.47; $\mathrm{H}, 5.15 ; \mathrm{N}, 6.61$.

1-[3-n-Butyl-5-(2-thienyl)phenyl]-4-methylpiperazine (71). Yield 26\%; ${ }^{1} \mathrm{H}-\mathrm{NMR}: \delta 7.25(\mathrm{~m}, 2 \mathrm{H}), 7.05(\mathrm{~m}$, $1 \mathrm{H}), 6.97(\mathrm{t}, J=2.0 \mathrm{~Hz}, 1 \mathrm{H}), 6.94,(\mathrm{~s}, 1 \mathrm{H}), 6.70(\mathrm{~s}, 1 \mathrm{H}), 3.25(\mathrm{t}, J=5.2 \mathrm{~Hz}, 4 \mathrm{H}), 2.59(\mathrm{~m}, 6 \mathrm{H}), 2.60(\mathrm{~s}$, 3H), 1.59 9M, 2H), $1.37(\mathrm{~m}, 2 \mathrm{H}), 0.93(\mathrm{t}, J=7.2 \mathrm{~Hz}, 3 \mathrm{H}) ;{ }^{13} \mathrm{C}-\mathrm{NMR}: \delta 151.9,145.4,144.6,135.2,127.9$, 124.6, 123.1, 118.3, 115.9, 111.5, 55.3, 49.4, 46.3, 36.2, 33.8, 22.7, 14.2. HR-MS (ESI). Calcd for $\mathrm{C}_{19} \mathrm{H}_{27} \mathrm{~N}_{2} \mathrm{O}$ $\left(\mathrm{M}^{+}+1\right): m / z$ 315.1895. Found: $m / z$ 315.1885. A hydrobromide salt: m.p. $234-236{ }^{\circ} \mathrm{C}$. Anal. Calcd for $\mathrm{C}_{19} \mathrm{H}_{26} \mathrm{~N}_{2} \mathrm{~S} \bullet 1.5 \mathrm{HBr}$ : C, 52.36; H, 6.36; N, 6.34. Found: C, 52.01; H, 6.40; N, 6.50.

\section{Conclusions}

Piperazin-1-yl substituted unfused heterobiaryls incorporating 4-(3-furyl) moiety demonstrate high affinities for $5-\mathrm{HT}_{7}$ receptor. The SAR studies on the model ligand 4-(3-furyl)-2-(4methylpiperazin-1-yl)pyrimidine $(2)\left(K_{\mathrm{i}}=7.2 \mathrm{nM}\right)$ revealed that introduction of an alkyl group to position 6 of the pyrimidine leads to increase in the binding affinity, however, a substituent at position 5 is highly detrimental. It was also shown that the pyrimidine core can be replaced with a pyridine ring without a significant loss of the binding affinity, although piperazine moiety is optimal, as its 
replacement results in decreased 5- $\mathrm{HT}_{7}$ affinity. The selected 6-ethylpyrimidine $\mathbf{1 2}\left(K_{\mathrm{i}}=7.1 \mathrm{nM}\right)$ and 6-butylpyrimidine $13\left(K_{\mathrm{i}}=1.6 \mathrm{nM}\right)$ ligands demonstrated $5-\mathrm{HT}_{7}$ antagonistic properties in cAMP functional test $\left(K_{\mathrm{B}}=12\right.$ and $60 \mathrm{nM}$, respectively). The extended selectivity studies with use of other types of serotonin $\left(5-\mathrm{HT}_{1 \mathrm{~A}}, 5-\mathrm{HT}_{2 \mathrm{~A}}, 5-\mathrm{HT}_{6}\right)$ and dopamine $\mathrm{D}_{2}$ receptors showed that compound 12 displays also pronounced affinity for $5-\mathrm{HT}_{2 \mathrm{~A}}$ receptors $\left(K_{\mathrm{i}}=12 \mathrm{nM}\right)$, which is consistent with our previous studies of piperazin-1-yl substituted heterobiaryl derivatives. 6-Butylpyrimidine analog 13 lacks selectivity towards $5-\mathrm{HT}_{2 \mathrm{~A}}, 5-\mathrm{HT}_{6}$ and dopamine $\mathrm{D}_{2}$ receptors. In summary, piperazin-1-yl substituted heterobiaryls constitute a potent group of serotonergic agents that could be further studied in animal models of CNS disorders.

Acknowledgments: This work was supported by the Program in Brains and Behavior at Georgia State University (L.S.) and, in part, by the Polish Ministry of Science and Higher Education, Grant No. 2-P05F-019-30 (A.J.B.)

Author Contributions: The structural design of compounds, the design of synthetic routes to compounds, and analysis of data were conducted by L.S. at Georgia State University. Compounds were synthesized and purified by his graduate students E.A.R., N.T.F., J.K., S.P., A.L.B., A.J.E., S.B., T.C.B., S.M.S. and his postdoctoral research associate A.R. A substantial amount of work indicated above was provided by J.S. a visiting professor to the L.S. research group and subsequently an independent researcher at the Medical University of Gdańsk. Compounds were assayed at the National Institutes of Health, Bethesda, USA and by G.S. in the A.J.B. laboratories using the same procedures. A.J.B. helped analyze the affinity results. L.S., J.S. and A.J.B. wrote the manuscript.

Conflicts of Interest: The authors declare no conflict of interest.

\section{References}

1. Murphy, D.L.; Campbell, I.C.; Costa, J.L. The brain serotonergic system in the affective disorders. Prog. Neuropsychopharmacol. 1978, 2, 5-31. [CrossRef]

2. Romero, L.; Hervás, I.; Artigas, F. The 5- $\mathrm{HT}_{1 \mathrm{~A}}$ antagonist WAY-100635 selectively potentiates the presynaptic effects of serotonergic antidepressants in rat brain. Neurosci. Lett. 1996, 219, 123-126. [CrossRef]

3. Tohgi, H.; Abe, T.; Takahashi, S.; Kimura, M.; Takahashi, J.; Kikuchi, T. Concentrations of serotonin and its related substances in the cerebrospinal fluid in patients with Alzheimer type dementia. Neurosci. Lett. 1992, 141, 9-12. [CrossRef]

4. Kepe, V.; Barrio, J.R.; Huang, S.C.; Ercoli, L.; Siddarth, P.; Shoghi-Jadid, K.; Cole, G.M.; Satyamurthy, N.; Cummings, J.L.; Small, G.W.; et al. Serotonin 1A receptors in the living brain of Alzheimer's disease patients. PNAS 2006, 103, 702-707. [CrossRef] [PubMed]

5. Baou, M.; Boumba, V.A.; Petrikis, P.; Rallis, G.; Vougiouklakis, T.; Mavreas, V. A review of genetic a psychotic diseases and response to atypical antipsychotics. Schizophr. Res. 2015, 170, 18-29. [CrossRef] [PubMed]

6. Berger, M.; Gray, J.A.; Roth, B.L. The expanded biology of serotonin. Annu. Rev. Med. 2009, 60, 355-366. [CrossRef] [PubMed]

7. Sprouse, J.; Reynolds, L.; Li, X.; Braselton, J.; Schmidt, A. 8-OH-DPAT as a 5-HT 7 agonist: phase shifts of the circadian biological clock through increases in cAMP production. Neuropharmacology 2004, 46, 52-62. [CrossRef] [PubMed]

8. Glass, J.D.; Grossman, G.H.; Farnbauch, L.; DiNardo, L. Midbrain raphe modulation of nonphotic circadian clock resetting and 5-HT release in the mammalian suprachiasmatic nucleus. J. Neurosci. 2003, 23, 7451-7460. [PubMed]

9. Hedlund, P.B.; Kelly, L.; Mazur, C.; Lovenberg, T.; Sutcliffe, J.G.; Bonaventure, P. 8-OH-DPAT acts on both 5- $\mathrm{HT}_{1 \mathrm{~A}}$ and 5- $\mathrm{HT}_{7}$ receptors to induce hypothermia in rodents. Eur. J. Pharmacol. 2004, 487, 125-132. [CrossRef] [PubMed]

10. Faure, C.; Mnie-Filali, O.; Scarna, H.; Debonnel, G.; Haddjeri, N. Effects of the 5- $\mathrm{HT}_{7}$ receptor antagonist SB-269970 on rat hormonal and temperature responses to the $5-\mathrm{HT}_{1 \mathrm{~A} / 7}$ receptor agonist 8-OH-DPAT. Neurosci. Lett. 2006, 404, 122-126.

11. Sarkisyan, G.; Hedlund, P.B. The $5-\mathrm{HT}_{7}$ receptor is involved in allocentric spatial memory information processing. Behav. Brain Res. 2009, 202, 26-31. [CrossRef] [PubMed]

12. Meneses, A. Effects of the 5-HT $-\mathrm{HT}_{7}$ receptor antagonists SB-269970 and DR 4004 in autoshaping Pavlovian/instrumental learning task. Behav. Brain Res. 2004, 155, 275-282. [CrossRef] [PubMed] 
13. Perez-Garcia, G.S.; Meneses, A. Effects of the potential 5-HT 7 receptor agonist AS 19 in an autoshaping learning task. Behav. Brain Res. 2005, 163, 136-140. [CrossRef] [PubMed]

14. Abbas, A.I.; Hedlund, P.B.; Huang, X.P.; Tran, T.B.; Meltzer, H.Y.; Roth, B.L. Amisulpride is a potent 5-HT 7 antagonist: relevance for antidepressant actions in vivo. Psychopharmacology 2009, 205, 119-128. [CrossRef] [PubMed]

15. Mullins, U.L.; Gianutsos, G.; Eison, A.S. Effects of antidepressants on 5-HT 7 receptor regulation in the rat hypothalamus. Neuropsychopharmacology 1999, 21, 352-367. [CrossRef]

16. Sarkisyan, G.; Roberts, A.J.; Hedlund, P.B. The 5-HT(7) receptor as a mediator and modulator of antidepressant-like behavior. Behav. Brain Res. 2010, 209, 99-108. [CrossRef] [PubMed]

17. Kusumi, I.; Boku, S.; Takahashi, Y. Psychopharmacology of atypical antipsychotic drugs: From the receptor binding profile to neuroprotection and neurogenesis. Psychiatry Clin. Neurosci. 2015, 69, 243-258. [CrossRef] [PubMed]

18. Sanchez, C.; Asin, K.E.; Artigas, F. Vortioxetine, a novel antidepressant with multimodal activity: Review of preclinical and clinical data. Pharmacol. Ther. 2015, 145, 43-57. [CrossRef] [PubMed]

19. Di Pilato, P.; Niso, M.; Adriani, W.; Romano, E.; Travaglini, D.; Berardi, F.; Colabufo, N.A.; Perrone, R.; Laviola, G.; Lacivita, E.; et al. Selective agonists for serotonin $7\left(5-\mathrm{HT}_{7}\right)$ receptor and their applications in preclinical models: an overview. Rev. Neurosci. 2014, 25, 401-415. [CrossRef] [PubMed]

20. Hołuj, M.; Popik, P.; Nikiforuk, A. Improvement of ketamine-induced social withdrawal in rats: The role of 5-HT7 receptors. Behav. Pharmacol. 2015, 8, 766-775. [CrossRef] [PubMed]

21. Nikiforuk, A.; Kos, T.; Fijał, K.; Hołuj, M.; Rafa, D.; Popik, P. Effects of the selective 5-HT 7 receptor antagonist SB-269970 and amisulpride on ketamine-induced schizophrenia-like deficits in rats. PLOS ONE 2013, 8, e66695. [CrossRef] [PubMed]

22. Leopoldo, M.; Lacivita, E.; Berardi, F.; Perrone, R.; Hedlund, P.B. Serotonin 5-HT 7 receptor agents: Structure-activity relationships and potential therapeutic applications in central nervous system disorders. Pharmacol. Ther. 2011, 129, 120-148. [CrossRef] [PubMed]

23. Żmudzki, P.; Satała, G.; Chłoń-Rzepa, G.; Bojarski, A.J.; Popik, P.; Zajdel, P. $\mathrm{N}$-(4-Arylpiperazinoalkyl)acetamide derivatives of 1,3- and 3,7-dimethyl-1H-purine-2,6(3H,7H)-diones and their 5- $\mathrm{HT}_{6}, 5-\mathrm{HT}_{7}$, and D2 receptors affinity. Heterocycl. Commun. 2015, 21, 13-18. [CrossRef]

24. Mokrosz, M.J.; Duszyńska, B.; Kłodzińska, A.; Dereń-Wesołek, A.; Chojnacka-Wójcik, E.; Baranowski, T.C.; Abdou, I.M.; Redmore, N.P.; Strekowski, L. 4-(3-furyl)-2-(4-methylpiperazino)pyrimidines: Potent 5-HT $2 \mathrm{~A}$ receptor antagonists. Bioorg. Med. Chem. Lett. 1997, 7, 1635-1638. [CrossRef]

25. Harden, D.B.; Mokrosz, M.J.; Strekowski, L. Addition and substitution reactions of chloropyrimidines with lithium reagents. J. Org. Chem. 1988, 53, 4137-4140. [CrossRef]

26. Strekowski, L.; Dworniczak, M.; Kowalewski, A. Dialkylamino Derivatives of Pyrimidine and Pyridine. Pol. J. Chem. 1980, 54, 1557-1560.

27. Saczewski, J.; Paluchowska, A.; Klenc, J.; Raux, E.; Barnes, S.; Sullivan, S.; Duszynska, B.; Bojarski, A.J.; Strekowski, L. Synthesis of 4-substituted 2-(4-methylpiperazino)pyrimidines and quinazoline analogs as serotonin 5- $\mathrm{HT}_{2 \mathrm{~A}}$ receptor ligands. J. Heterocycl. Chem. 2009, 46, 1259-1265. [CrossRef]

28. Raux, E.; Klenc, J.; Blake, A.; Saczewski, J.; Strekowski, L. Conjugate Addition of Nucleophiles to the Vinyl Function of 2-Chloro-4-vinylpyrimidine Derivatives. Molecules 2010, 15, 1973-1984. [CrossRef] [PubMed]

29. Mokrosz, J.L.; Strekowski, L.; Duszynska, B.; Harden, D.B.; Mokrosz, M.J.; Bojarski, A.J. Structure-activity relationship studies of CNS agents. Part 14: Structural requirements for the 5- $\mathrm{HT}_{1 \mathrm{~A}}$ and 5- $\mathrm{HT}_{2 \mathrm{~A}}$ receptor selectivity of simple 1-(2-pyrimidinyl)piperazine derivatives. Pharmazie 1994, 49, 801-806. [CrossRef] [PubMed]

30. Mokrosz, M.J.; Strekowski, L.; Kozak, W.X.; Duszynska, B.; Bojarski, A.J.; Klodzinska, A.; Czarny, A.; Cegla, M.T.; Deren-Wesolek, A.; Chojnacka-Wójcik, E.; et al. Structure-Activity Relationship Studies of CNS Agents, Part 25: 4,6-Di(heteroaryl)-2-(N-methylpiperazino)pyrimidines as New, Potent 5- $\mathrm{HT}_{2 \mathrm{~A}}$ Receptor Ligands: A Verification of the Topographic Model. Arch. Pharm. 1995, 328, 659-666. [CrossRef]

31. Paluchowska, M.H.; Bugno, R.; Duszynska, B.; Tatarczynska, E.; Nikiforuk, A.; Lenda, T.; Chojnacka-Wojcik, E. The influence of modifications in imide fragment structure on 5-HT(1A) and 5-HT(7) receptor affinity and in vivo pharmacological properties of some new 1-( $m$-trifluoromethylphenyl)piperazines. Bioorg. Med. Chem. 2007, 15, 7116-7125. [CrossRef] [PubMed] 
32. Lovell, P.J.; Bromidge, S.M.; Dabbs, S.; Duckworth, D.M.; Forbes, I.T.; Jennings, A.J.; King, F.D.; Middlemiss, D.N.; Rahman, S.K.; Saunders, D.V.; et al. A Novel, Potent, and Selective 5-HT 7 Antagonist: (R)-3-(2-(2-(4-Methylpiperidin-1-yl)-ethyl)pyrrolidine-1-sulfonyl)phenol (SB-269970). J. Med. Chem. 2000, 43, 342-345. [CrossRef] [PubMed]

33. Canale, V.; Kurczab, R.; Partyka, A.; Satala, G.; Lenda, T.; Jastrzebska-Wiesek, M.; Wesolowska, A.; Bojarski, A.J.; Zajdel, P. Towards new 5-HT7 antagonists among arylsulfonamide derivatives of (aryloxy)ethyl-alkyl amines: Multiobjective based design, synthesis, and antidepressant and anxiolytic properties. Eur. J. Med. Chem. 2016, 108, 334-346. [CrossRef] [PubMed]

34. Zajdel, P.; Kurczab, R.; Grychowska, K.; Satała, G.; Pawłowski, M.; Bojarski, A.J. The multiobjective based design, synthesis and evaluation of the arylsulfonamide/amide derivatives of aryloxyethyl- and arylthioethyl- piperidines and pyrrolidines as a novel class of potent 5-HT7 receptor antagonists. Eur. J. Med. Chem. 2012, 56, 348-360. [CrossRef] [PubMed]

35. Roth, B.L. The Serotonin Receptors; Springer: Berlin, Germany, 2006; pp. 39-58.

36. Samaritoni, J.G.; Babbitt, G.E. Synthesis of 2-(4-quinazolinyl)ethyl sulfides via addition of thiols to 4-vinylquinazolines. J. Heterocycl. Chem. 1997, 34, 1263-1266. [CrossRef]

Sample Availability: Not Available.

(c) 2016 by the authors; licensee MDPI, Basel, Switzerland. This article is an open access article distributed under the terms and conditions of the Creative Commons by Attribution (CC-BY) license (http://creativecommons.org/licenses/by/4.0/). 